A PRIMARY CARE-BASED SPANISH PARENTING INTERVENTION TO

ADDRESS BEHAVIORAL PROBLEMS IN CHILDREN: A STUDY OF

FEASIBILITY AND BARRIERS

by

\title{
LISA YSELA RAMIREZ
}

Submitted in partial fulfillment of the requirements for the degree of

Doctor of Philosophy

Dissertation Advisor: Terry Stancin, Ph.D., Metro Health Medical Center

Department of Psychology

CASE WESTERN RESERVE UNIVERSITY

August, 2011 


\section{CASE WESTERN RESERVE UNIVERSITY \\ SCHOOL OF GRADUATE STUDIES}

We hereby approve the dissertation of Lisa Ysela Ramirez, M.A., candidate for the Doctor of Philosophy in Psychology degree *.

H. Gerry Taylor, Ph.D., ABPP, (chair of the committee)

Terry Stancin, Ph.D.

Arin Connell, Ph.D.

Norah Feeny, Ph.D.

May 19, 2010

*We also certify that written approval has been obtained for any proprietary material contained therein. 


\section{Dedication Page}

This dissertation is dedicated to my loving parents, Juanita and Robert.

You are the ultimate role models and your unconditional love and support has allowed me to follow my dreams. 
Table of Contents

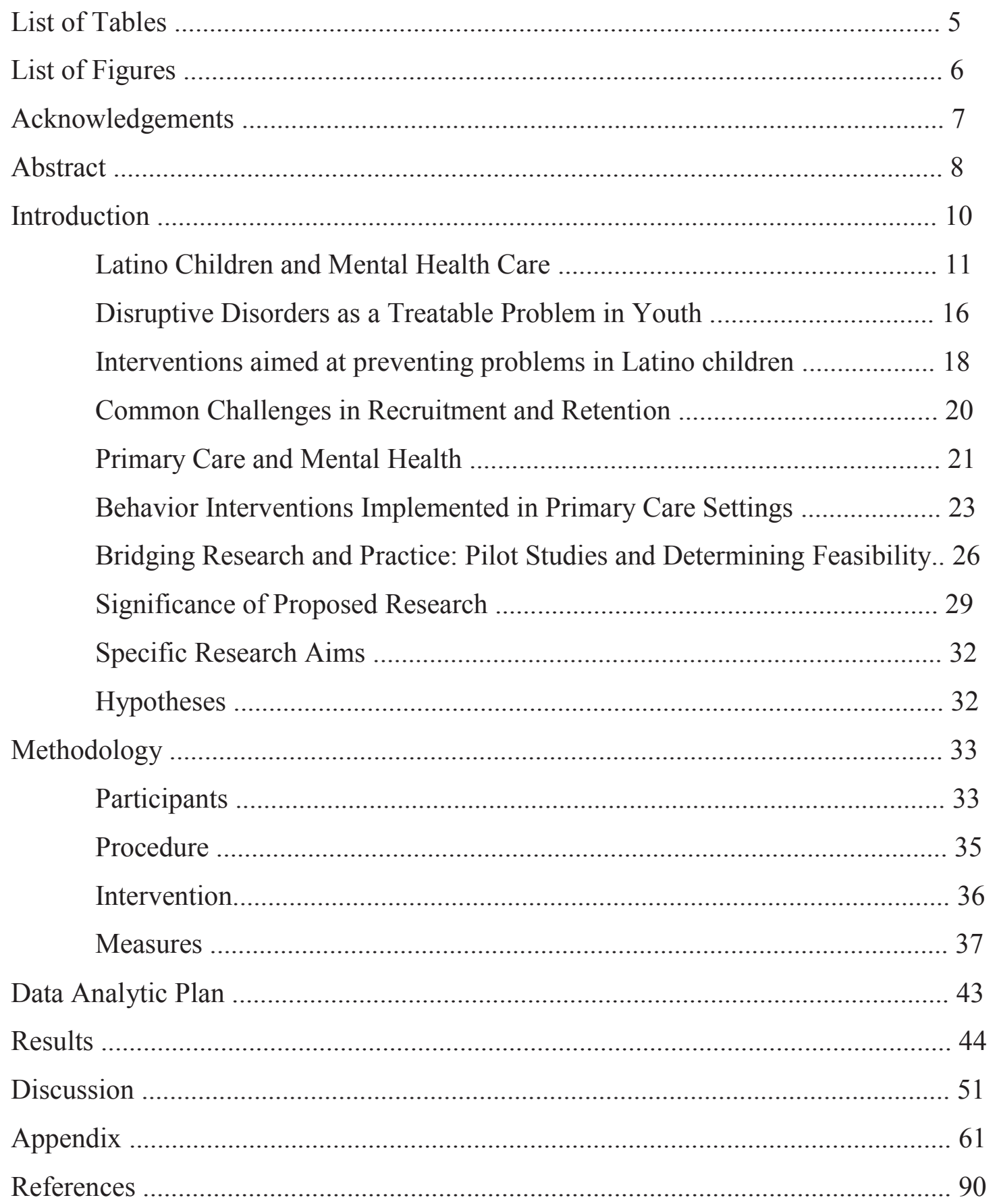


List of Tables

Table 1. Benefits of primary care mental health interventions for Latinos 61

Table 2. Demographics of intervention sample ..... 62

Table 3. Content of Chicago Parenting Program 63

Table 4. Psychometric properties of outcome measures 64

Table 5. Parent-reported reasons for refusal to participate in program .......................... 65

Table 6. Reasons parents did not attend sessions despite expressing interest............... 66

Table 7. Breakdown by percentage of parent interest/disinterest/attendance.............. 67

Table 8. Summary of weekly and final program evaluations ................................... 68

Table 9. Summary of weekly satisfaction ratings Baseline/post-intervention PSOC, EBI,

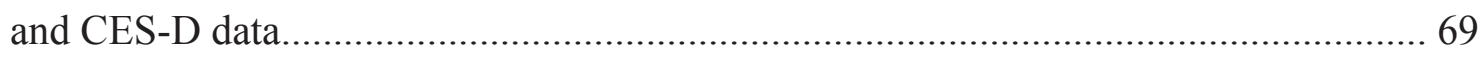

Table 10. Baseline/post-intervention Child Behavior CheckList (CBCL) data ........... 70

Table 11. Baseline/post-intervention Parenting Sense of Competency (PSOC) data.... 71

Table 12. Baseline/post-intervention Parenting Practices (PARTS) data..................... 72

Table 13. Baseline/post-intervention Center for Epidemiological Studies Depression

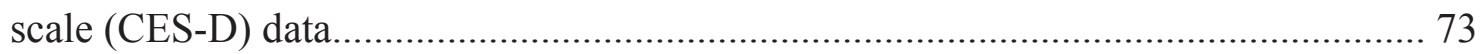

Table 14. Hispanic clinic staff feedback regarding intervention................................. 74

Table 15. Lessons learned from study............................................................. 75 


\section{List of Figures}

Figure 1. Recruitment and intervention...................................................... 76

Figure 2. CBCL Total baseline (pre) and post-intervention T-scores.................... 77

Figure 3. CBCL Externalizing baseline (pre) and post-intervention T-scores........ 78

Figure 4. CBCL Internalizing baseline (pre) and post-intervention T-scores........ 79

Figure 5. CBCL Attention baseline (pre) and post-intervention T-scores............. 80

Figure 6. CBCL Aggression baseline (pre) and post-intervention T-scores.......... 81

Figure 7. PSOC Total baseline (pre) and post-intervention scores...................... 82

Figure 8. PSOC Satisfaction baseline (pre) and post-intervention scores.............. 83

Figure 9. PSOC Effectiveness baseline (pre) and post-intervention scores........... 84

Figure 10. PARTS Total baseline (pre) and post-intervention scores................... 85

Figure 11. PARTS Laxness baseline (pre) and post-intervention scores............... 86

Figure 12. PARTS Overreactivity baseline (pre) and post-intervention scores ..... 87

Figure 13. PARTS Verbosity baseline (pre) and post-intervention scores ............ 88

Figure 14. CES-D baseline (pre) and post-intervention scores .......................... 89 


\section{Acknowledgments}

I sincerely wish to thank the study participants for their interest and participation in this intervention. I would like to acknowledge and thank MetroHealth Medical Center and their Hispanic Pediatric Primary Care Clinic for welcoming me with open arms and allowing me to conduct my research. And I would like to acknowledge my dedicated undergraduate research assistants, Julia Obejero-Paz, Roshni Rao, and Emily Newton, for their interest in the project.

I am grateful for my committee members who were very generous with their guidance and expertise from the beginning to the completion of the project. Thank you to Denny Drotar and Gerry Taylor, my departmental advisors, for the years of support and encouragement. A special thanks to Terry Stancin for her mentorship, flexibility, and patience throughout the entire dissertation process.

I would like to express my gratitude for my graduate school department - the community that has fostered my development, and my clinical supervisors who have encouraged me to take risks and develop my identity as a young therapist and patient advocate.

Last, but not least, thank you to my friends and family. First and foremost, my partner-in-crime, Samantha Huestis, with whom I have spent the last five years navigating the waters of graduate school and personal challenges. Your friendship has been an absolute gift that I will carry with me as we continue along our individual career paths. Thank you to my best friends, Julie S. Hussain and Jay Shah, for being my loudest cheerleaders. Finally, nothing would be possible without the unconditional support of my family in Texas - even the distance could not lessen the power of your love and excitement. 
A Primary Care-Based Spanish Parenting Intervention to Address Behavioral Problems in Children: A Study of Feasibility and Barriers

\author{
Abstract \\ by

\section{LISA YSELA RAMIREZ}

Introduction and Background: Latino children living in the United States are at increased risk for behavioral problems than their non-Latino peers (Coatsworth, Pantin, \& Szapoznik, 2002), yet fewer than $25 \%$ receive the mental health care they need (Alegria, Mulvaney-Day, Woo, Torres, \& Gao, 2007). Behavior disorders respond well to early childhood intervention (Lochman, 2000), and primary care clinics are emerging as innovative and effective settings for detecting and providing interventions for child behavior problems even before children begin school (Stancin, Perrin \& Ramirez, 2009). The current study implemented a behavioral parenting intervention in a pediatric primary care clinic specializing in treating Latino, mainly Puerto Rican, bilingual patients. The outcome of this study focused on assessing feasibility of implementation, including evaluating desirability, acceptance and effectiveness of the intervention. Methodology: The Chicago Parenting Program (CPP), a validated behavioral parenting intervention, was pilot tested in the MetroHealth Medical Center Hispanic Pediatric. Forty-four Latino parents with children aged 2-8 years were screened. Measures included weekly acceptance and helpfulness ratings, pre- and post-intervention responses on the Spanish versions of the Child Behavior CheckList, the Parenting Sense 
of Competency, and the Parenting Practices Scale, and the Center for Epidemiologic Studies scale for Depression, and the Therapy Attitude Inventory.

Results: Forty-four Latino parents of children were approached and screened for child behavior concerns. Thirty-five parents endorsed concern, 23 parents were interested in the intervention and 9 eventually participated. A total of 6 mothers completed the parenting intervention, which was rated as useful, desirable, and associated with an increase in parenting satisfaction and trends toward a decrease in maternal depression and child internalizing symptoms.

Discussion: Spanish-language primary care-based parenting groups were shown to be feasible and future research should focus on how to maximize the effectiveness of the intervention. 
A primary care-based Spanish parenting intervention to address behavioral problems in children: A study of feasibility and barriers

\section{Introduction and Background}

As many as 5-20\% of American children aged 0-17 years have an emotional, developmental, or behavioral problem that will to persist at least 12 months. In children younger than 5 years of age, the most common diagnosable problems include speech $(6 \%)$, learning $(3 \%)$ and behavior $(2 \%)$ difficulties, while at least $21 \%$ of parents of children younger than 5 years report concerns about their child's behavior (Blanchard, Gurka, \& Blackman, 2005; Coard \& Holden, 1998). According to a national report released in 1999 by the Surgeon General, 21\% of 9-17 year-old American children met criteria for a diagnosable mental disorder, with the two most common problems being anxiety disorders (13\%) and disruptive behavior disorders (DBD) (10\%) (US Department of Health and Human Services, USDHHS, 1999). Alarmingly, the majority of parents reported some problem in attaining resources, and as few as half of the caregivers of children exhibiting psychosocial difficulties reported receiving mental health services (Blanchard, Gurka, \& Blackman, 2005). Consequently, there has been increasing interest in providing behavioral services in more accessible settings, such as primary care clinics (Stancin, Perrin, \& Ramirez, 2009).

Latino children and caregivers in the United States experience greater difficulties and demonstrate lower rates of help-seeking behaviors than non-Latinos (Flores, Fuentes-Afflick, Barbot, Carter-Pokras, Claudio et al., 2002). Despite efforts to increase cultural competency and education among mental health providers and consumers, disparities in rates of psychosocial problems and access to mental health 
services continue to plague Latino individuals living in the United States. Rates of DD and more serious behavior problems, including conduct disorder (CD) and substance abuse are especially high among Latinos (Coatsworth, Pantin, \& Szapoznik, 2002). The proposed study will evaluate the feasibility of providing Spanish language behaviorfocused parent-management intervention groups to alleviate a portion of the demand for mental health services from Spanish-speaking mental health providers and provide more cost-effective service alternatives for Spanish-speaking parents concerned about their child‘s behavior.

\section{Latino Children and Mental Health Care}

Latinos comprised 15 percent of the American population as of 2007, and are projected to constitute $24 \%$ of the population by the year 2050 (US Census Bureau, 2008a). Latinos are struggling in many areas of American life due to lower high school graduation rates and higher rates of crime and incarceration, teenage pregnancy, and single-parent households than non-Latino, Caucasian counterparts (Masi, Hawkley, Piotrowski, \& Pickett, 2007). Additionally, rates of depression, conduct problems and anxiety are steadily increasing in Latino youth (Flores et al., 2002; USDHHS, 2001). Various models attempt to account for these impairments, including Latinos acculturative stress (Dressler \& Bernal, 1982; Loukas, Suizzo, Prelow, 2007), differing cultural value systems (Smokowski and Bacallao, 2006), decreased access to satisfactory educational services (Wood, Yeh, Pan, Lambros, McCabe \& Hough, 2005), and unsupportive or harsh parenting practices (Manongdo and Garcia, 2007). 
Research consistently demonstrates that the rate of mental health problems in Latino children continues to rise (Flores et al., 2002), and maternal and child acculturation, or the conflict between ethnic and cultural identification versus identification with mainstream American practices, has been extensively researched as a powerful risk factor for childhood psychosocial problems in Latino populations (Cortes, Rogler, \& Malgady, 1994). Latinos experience stress in relation to this process, which is associated with poor health outcomes and high rates of behavioral problems in children (Dressler \& Bernal, 1982). Several studies suggest that the association of parenting practices with adolescent psychosocial outcomes depends in part on the level of acculturation, with parenting showing the expected association with outcomes only in parents at higher levels of acculturation. (Ho, Yeh, McCabe, \& Hough, 2007; Loukas, Suizzo, Prelow, 2007; Smokowski and Bacallao, 2006). Acculturative stress may manifest differentially across Latino ethnic groups. Research has found that Mexicans tend to struggle initially with the transition into American life but assimilate rather quickly while Puerto Rican individuals experience less stress initially but tend to have difficulty completely assimilating into mainland American culture, most likely due to the ease and frequency of travel between Puerto Rico and the mainland (Arcia, Skinner, Bailey \& Correa, 2001). Similarly, Pachter, Auinger, Palmer and Weitzman (2006) proposed that culturally bound parenting practices and the high rates of maternal depression, associated with acculturative stress in Latinos, account for more problems in children's behavior than the risks conferred from living in poverty. Further, maternal depression has been associated with increased rates of DBD in children (Harnish, Dodge, \& Valente, 1995). Nonetheless, the impoverished environments inhabited by 
Latinos also put Latino youth at higher risk for psychosocial problems (Belitz \& Valdez, 1997).

In addition to differences in rates of psychosocial problems, Latinos exhibit complicated attitudes toward mental health resources and services. Arcia, Fernandez, Jaquez, Castillo and Ruiz (2004) interviewed Latino mothers about their feelings towards accessing mental health services and uncovered common themes of unawareness of mental health resources, embarrassment about their child's behavior problems, and feelings of incompetence when seeking out and following through with referrals for mental health services. Further, only one-third of the mothers interviewed in this study actively sought services while more than half of the mothers sought services only after encouragement from multiple sources, including their family, friends, and/or their child's school. Cauce, Domenech-Rodriguez, Paradise, Cochran, Shea, Srebnik et al. (2002) highlighted the existence of differences in cultural perceptions of what problems necessitate intervention by a mental health professional, and from where help is sought. Ethnic minorities are less likely to seek specialized mental health services and are more likely to use alternative sources of care, usually from school staff (40\%) and primary care physicians (11\%), perpetuating disparities in psychosocial problems (Cook, McGuire \& Miranda, 2007). Latinos also demonstrate strong cultural treatment preferences. Cunningham, Bremner and Boyle (1995) discovered that Latino parents often prefer group therapy settings to individual therapy in order to reduce the stigma and embarrassment associated with seeking mental health services. Additionally, Latinos generally prefer that their providers also be Latinos, which is rarely possible given the relative lack of Latino mental health providers 
(Flores, et al., 2002), especially in the central and northern parts of the US. Further, even if Latino individuals initiate contact with mental health providers, premature termination of psychotherapy is associated with ethnic minority status, lower educational attainment and low SES (Wierzbicki \& Pekarick, 1993). As Ho et al. (2007) advocated, more minority-focused outreach programs are needed to recruit atrisk minority populations into culturally sensitive prevention and intervention programs. Chow, Jaffee, and Snowden (2003) explored various factors assumed to determine Latinos` decreased rates of mental health service utilization, including limited insurance coverage, cultural biases regarding mental health, limited access to competent service providers, and high rates of poverty. The authors elucidated how community poverty is associated with a lack of adequate social services and often drives community residents to public hospitals for mental health services, which in turn places further strains on these resources. The authors also point out that community resources targeting minority populations are more likely to attract and retain minorities. This suggests that institutions with limited resources may be better served to target the specific populations they seek to help.

Alarmingly, Alegria, Mulvaney-Day, Woo, Torres and Gao (2007) found that as few as $20 \%$ of non-immigrant Latinos with psychosocial problems seek general mental health services and as few as 9\% of non-immigrant Latinos with serious mental illnesses receive specialty mental health care. These investigations also found that only $3 \%$ of primarily Spanish-speaking Latinos accessed mental health services over the preceding year, compared to $5-8 \%$ of bilingual or English speaking Latinos (Alegria et al. 2007). Limited-English proficiency individuals are less likely to receive needed 
mental health services, even after controlling for race, poverty, and insurance status (Sentell, Shumway, \& Snowden, 2007). The enormity of this problem is underscores by the fact that, and as of $2007,12 \%$ of U.S. residents spoke primarily Spanish in their homes (US Census, 2008b). Further, at-risk ethnic minority children are often identified at later ages than Caucasian children as needing school-based services, which is often a point of entry for children needing specialty mental health services (Wood et al., 2005).

Whether due to lack of access to or negative attitudes about mental health services, one study of juvenile offenders found that Latino juveniles exhibited more conduct disordered and oppositional behavior than their non-Latino Caucasian counterparts, yet had less than one-third the rate of a prior treatment history (Rawal, Romansky, Jenuwine \& Lyons, 2004). Echoing the findings of Pachter et al. (2006), it is worth noting that the pathways for entry into the juvenile justice system appear to be distinct for Latinos. In contrast to higher rates of maternal depression, acculturation, lack of access to mental health resources in this ethnic groups, African Americans had lower caregiver and more family impairment, and non-Latino Caucasians had higher rates of substance use (Rawal et al., 2004; Yasui and Dishion, 2007). These studies highlight that mental health problems, especially DBD, are a major challenge facing Latino parents and an already overloaded juvenile justice system. Since behavior problems are effectively treated with early intervention, providing accessible mental health resources to Latino parents with behavioral concerns about their children is crucial to reducing disparities in rates of DBD in Latino youth. 


\section{Disruptive Behavior Disorders as a Treatable Problem in Youth}

DBD include diagnoses such as CD in older children, as well as Oppositional Defiant Disorder (ODD), characterized by defiance and hostility in young children, both of which are accompanied by functional impairment. Defiant behavior tends to emerge early (before age 8 years) and remain stable without intervention; children who exhibit signs of oppositionality in early childhood tend to display similar behaviors into early adolescence (APA, 2000) and are at risk for later substance abuse, violence against others, depression and suicidality, and poor/neglectful parenting practices (Tremblay, Nagin, Seguin, Zoccolillo, Zelazo et al., 2004). The etiology of DBD appears to be one of equifinality, given that multiple yet distinct risk factors result in DBD (Cicchetti \& Rogosch, 1996). Models evaluating the path from early childhood DBD to later conduct-disordered behavior and substance abuse most commonly focus on environmental factors (especially parenting practices) and child temperament (APA, 2000; Lochman, 2000; Tremblay et al., 2004).

One of the strongest risk factors known to result in problem behaviors is inconsistent, overly permissive or overly harsh parenting (Bauer \& Webster-Stratton, 2006; Lochman, 2000; Yasui and Dishion, 2007), and parents of children with behavioral problems report feeling unable to cope with the daily demands of parenting (Blanchard, Gurka, \& Blackman, 2005). Additionally, annual costs (i.e., medications, mental health services, juvenile justice, school services, etc.) associated with treating ODD, can exceed $\$ 13,000$, while treating CD can cost over $\$ 26,000$ (Foster, Jones, and 
the Conduct Problems Prevention Research Group, 2005), underscoring the importance of prevention programs aimed at lessening problem behaviors.

Early childhood intervention (before 8-10 years of age) with DBD has been shown to be efficacious in alleviating defiant behaviors and preventing the development of CD (Bauer \& Webster-Stratton, 2006; Lochman, 2000). The best-established method for treating early conduct problems is training parents how to manage children's behavior and demands effectively (Lochman, 2000; USDHHS, 1999). Many parenting interventions aimed at diminishing behavior problems have proven efficacious in decreasing problem behavior, improving parenting practices and enhancing communication within families (Bauer \& Webster-Stratton, 2006; Kumpfer \& Alvarado, 2003; Lochman, 2000), especially when delivered to parents of children aged 3-10 years. Increases in parenting efficacy have been associated with decreases in child behavior problems and depression in parents, and is often effectively targeted in parenting interventions (Jones \& Prinz, 2005; Pisterman, Firestone, McGrath, Goodman, Webster, Mallory et al., 1992). Examples of successful programs include the Parent-Child Interaction Training (PCIT), which utilizes bug-in-the-ear coaching method (Eyberg \& Robinson, 1982); The Incredible Years Program, a series of standardized video vignettes and discussions provided to parents, children, and teachers (Webster-Stratton, 2000); and the Behavior Analysis Services Program (BASP), training which focuses on 8 key parenting skills (stay close, give positive consequences, ignore junk behavior, pivot, stop-redirect-GPQ, set expectations, use contract) using a 30-hour curriculum (Van Camp, Vollmer, Goh, Whitehouse, Reyes, Montgomery, \& Borrero, 2008). Parent training interventions are often delivered individually and/or in 
a group setting by mental health professionals. Cunningham, Bremner and Boyle (1995) evaluated the cost effectiveness of delivering parent training in a group versus individualized setting and discovered that group-format parent training interventions can be up to six times more cost-effective than individual parent-training, which is important to consider when there are limited resources. Further, some parents reported longer treatment gains following the group-format intervention than the individually based intervention (Cunningham, Bremner, \& Boyle, 1995). The success in efficacy studies is promising for child mental health providers and leads to a need for effectiveness and feasibility studies in multiple community settings and populations, especially for ethnic minority populations, as advocated by the Surgeon General (USDHHS, 1999).

\section{Interventions aimed at preventing problems in Latino children}

As Yasui and Dishion (2007) discussed, almost all prevention programs directed at child behavior are developed on majority culture and applied directly to minority populations without consideration for cultural adaptation. Several behavioral interventions have been developed or culturally adapted for implementation with Latino populations, with most interventions available in Spanish. Not only does this provide an accessible resource for parents, but fulfills Latino parents ${ }^{6}$ preference for group interventions as opposed to individual therapy sessions (Cunningham, Bremner, \& Boyle, 1995; Kumpfer \& Alvarado, 2003).

Coatsworth, Pantin and Szapoznik (2002) developed an intervention intended to prevent disruptive behaviors in Latino adolescents by helping parents to build a social 
network and culturally relevant effective parenting practices and skills. This program was shown to decrease substance abuse in adolescents, but was not designed for children with DBD.

Martinez and Eddy (2005) recently introduced a culturally sensitive parenting intervention, Nuestras Familias, which included innovative lessons in acknowledging Latino roots, discussing culturally determined roles in the family, bridging Latino and American culture, and discussing salient obstacles for Latino families. Positive outcomes for this intervention included improved parenting practices and enhanced youth adjustment, but the curriculum is not yet available for implementation in settings outside of the authors' institution.

Finally, the Chicago Parenting Program (CPP) was created as a culturally sensitive adaptation of the Incredible Years with the help of parent focus groups who recommended using diverse sets of parents engaged in daily parenting practices in the standard video vignettes (Gross, Julion, \& Garvey, 2003). The CPP was also developed to target families who may not receive mental health services otherwise and to offer behavioral intervention services in a setting that families know and trust, such as community centers. CPP has been offered in urban child-care and Head Start centers with good outcomes and has demonstrated success in serving large numbers of lowincome families (Breitenstein, Gross, Ordaz, Julion, Garvey \& Ridge, 2007). A major strength of the CPP is the accessibility of the intervention for mental health providers. CPP has a relatively inexpensive manualized curriculum, offered in English and Spanish, which is helpful for organizations that may not be able to afford the intensive 
training, materials, and sometimes travel, necessary to implement the Incredible Years or the Positive Parenting Program (PPP).

Notably, most studies on parenting interventions conducted in Latino populations have predominantly Mexican, or Mexican-American participants; little is known about the efficacy or effectiveness of culturally adapted parenting interventions on Caribbean (e.g., Cuban, Puerto Rican, and Dominican Republic) or South American Latinos. As Kumpfer and Alvarado (2003) emphasize, more research is needed to understand how validated interventions generalize to specific ethnic populations and what factors facilitate recruitment and retention (i.e., site of intervention, previous relationship with provider, on-site child-care, etc.).

\section{Common Challenges in Recruitment and Retention}

One consistent barrier to successful program implementation is effective recruitment and retention of participants. Interventions require time commitments, effort to attend the sessions, and continued attendance, which often increases attrition rates. Low SES families incur additional burdens of securing reliable transportation, child-care and taking time-off from jobs. Research demonstrates that providing childcare, transportation and food aids greatly in recruitment and retention (Kumpfer \& Alvarado, 2003). Interventions targeting Latino populations must consider these factors as well as possible pre-existing negative attitudes about mental health services and medical settings.

Nordstrom, Dumas, and Gitter (2008) identified several predictors for enrollment and attendance in a predominantly African-American sample of parents 
attending an intervention offered in a Head Start environment, which may be generalizable to Latino parents recruited for parenting interventions. The authors found that intention to enroll, or the expression of interest by parents, was best predicted by younger child age, higher perceived benefits of the intervention and low scheduling barriers with the intervention sessions, while actual enrollment and attendance was best predicted by child oppositional behaviors, maternal age, parenting efficacy, perceived benefits of and positive attributions to the intervention, trust in the intervention, and low demands and minimal scheduling conflicts. The study revealed that although mothers with higher parenting efficacy were more likely to enroll in the intervention, mothers with lower parenting efficacy were more likely to attend more sessions. These results imply that recruitment efforts targeted at encouraging mothers with lower perceived efficacy to attend at least one session may improve the overall outcomes of parenting interventions targeting oppositional behaviors in childhood.

\section{Primary Care and Mental Health}

Another area for exploration is evaluating various settings (e.g., primary care clinics, day care centers, schools, churches, etc.) for facility in recruitment and retention.

Primary care clinics are emerging as attractive settings for mental health interventions for a variety of reasons. Primarily, pediatricians have arguably more exposure to children younger than 5 years of age than any other professional, placing them in an optimal position to identify and refer parents to the appropriate resources when behavioral concerns arise (Bauer \& Webster-Stratton, 2006). Furthermore, 
behavior problems in childhood are [one of] the most common problems facing pediatricians and contribute to the bottleneck of services for mental health service providers, including increasing demand and the amount of time families must wait before having access to a provider (Hawkins-Walsh, 2001). Additionally, mothers are almost as likely to seek help for mental health concerns from their pediatrician as they would family or friends (Barlow, Wildman, \& Stancin, 2005). Finally, the entry point for mental health services for many children with behavior problems is school-based referrals. Primary care clinics have access to children several years before they enter the school system and are therefore able to identify children in need of, and potentially provide, early behavioral intervention services (Stancin, Perrin \& Ramirez, 2009).

The Surgeon General recently recommended co-locating psychological services within medical clinics to increase individuals' access to appropriate mental health services (USDHHS, 1999). Lieberman, Adalist-Estren and Sloan (2006) evaluated the impact of on-site mental health services on follow-through with pediatric mental health referrals, and found that $66 \%$ of patients followed through with referrals for on-site counseling, while only $2.6 \%$ of patients referred to off-site mental health resources saw a counselor. Discrepancies in the rates of mental health referrals and actual services received are commonly attributed to the seemingly acute nature of many childhood problems compared to long wait times for provider appointments, and mistrust of and unfamiliarity with mental health service resources (Lieberman et al., 2006). Considering these findings, providing mental health interventions within medical clinics may be a worthwhile investment for many primary care providers and may aid mental health providers in ensuring their services are offered most efficiently. 
Stevens and Lee (2003) advocated for a preventive focus in primary care settings, with specific attention paid to chronic mental health conditions. HawkinsWalsh (2001) reiterated the finding that children with behavioral problems have a higher frequency of pediatrician visits, which is time-consuming for physicians and more costly for insurance companies.

\section{Behavior Interventions Implemented in Primary Care Settings}

Capitalizing on the advantages of offering behavioral interventions in primary care, several organizations utilized these methods in primary settings with favorable outcomes. Lavigne, LeBailly, Gouze, Cicchetti, Pochyly et al. (2008b) compared the effectiveness of a well-established parent-training program, The Incredible Years, as delivered by two different professionals (psychologist versus nurse practitioner) compared to a literature-based intervention in treating children diagnosed with ODD. The authors discovered that all three conditions led to improvements children's functioning, but identified several interesting trends: nurse-led groups were more effective with parents of females than males, and the literature-based intervention group was more helpful to families with boys than families with girls. In addition, the psychologist-led groups were effective with all demographics, and this was the only condition to decrease ODD-symptoms effectively in male children whose parents had lower levels of education (Lavigne, LeBailly, Gouze, Cicchetti, Jessup, Arend, et al. 2008a).

Borowsky, Mozayeny, Stuenkel and Ireland (2004) evaluated the effect of an intervention aimed at preventing violent behaviors in children delivered in a primary 
care clinic and found that the intervention decreased the number of injuries sustained by children, the number of medical visits needed due to fights and violence, and the use of corporal punishment by the parents involved in the study. The authors advocated utilizing collaborative care between providers and continuing to implement parenttraining strategies in various medical settings. In addition to the Incredible Years, other established parent training interventions have demonstrated successful outcomes in primary care, including the PPP (Sanders, Turner, \& Markie-Dadds, 2002) and ParentChild Interaction Training (Neary \& Eyberg, 2002)

Behavioral interventions implemented in primary care targeted at reducing oppositional behaviors are effective for the populations they have been studied in: primarily middle-class, Caucasian samples, but have rarely been investigated in other ethnic groups. Latino children experience many factors that perpetuate disparities in utilization of and access to quality primary health care. Stevens and Lee (2003) proposed a theoretical model to explain disparities in primary care, which included limited insurance access and coverage, low SES, and cultural factors such as language proficiency and attitudes toward health care institutions and providers as the primary environmental factors affecting primary care experiences. Language factors contribute to limited care by preventing complete communication between the patients and providers, and disruption of care in many cases. Additionally, Latino family attitudes toward providers can be complicated by an emphasis on respect for medical providers coupled with a tendency to simply switch providers or institutions after a negative experience, continually disrupting the child's health care (Stevens \& Lee, 2003). However, Brown, Wissow, Zachary and Cook (2007) evaluated attitudes about 
accepting physician advice and referrals for child behavior problems and discovered that Latino parents were more likely than non-Latino African American and Caucasian parents to follow pediatricians' recommendations about child behavior-related concerns and posited that primary care may provide the optimal opportunity for intervention efforts with Latino parents. Table 1 summarized the benefit to Latinos of receiving mental health resources and care in a primary care setting.

Guevara, Rothbard, Shera, Zhao, Forrest, Kelleher and Schwartz (2007) reviewed screening, referral and treatment trends for Puerto Rican children presenting for primary care visits and highlighted that $41 \%$ of all identified problems were behavior/conduct problems. This trend is qualitatively replicated in a county hospital in Cleveland, Ohio: Metro Health Medical Center's Hispanic Clinic.

MetroHealth Medical Center's (MHMC) Hispanic Clinic is a comprehensive pediatric primary care center that provides medical, educational, and psychological consultation services to Spanish-speaking, primarily Puerto Rican, families (ElGhoroury, Ramirez \& Bonny, in preparation). The MHMC Hispanic Clinic physicians refer many Spanish-speaking families for psychological services to treat concerns about behavior, depression, anxiety, and other psychosocial issues. Consequently, MetroHealth Hospital's Child Psychology Department is inundated with referrals for Spanish-speaking families, but is limited in its ability to provide psychological services in Spanish. MetroHealth`s Hispanic Clinic and Child Psychology Department would benefit from a group-based, Spanish-language parenting intervention able to treat multiple families at a time and alleviate demand on the psychology providers working in these services. Ultimately, low-income families are most likely to receive medical 
care in hospital-based clinics (Kaizar, Chisolm, Seltman, Greenhouse, Kelleher, 2006), which further supports the need to implement parenting-interventions in community hospital settings with high percentages of Latino patients. These settings have a huge volume of Latino families with concerns of their children's behavior and established relationships with primary care health professionals. For these reasons, MHMC's Hispanic Clinic is the ideal setting for a community-based feasibility study evaluating the impact of parenting-intervention groups.

Bridging Research and Practice: Pilot Studies and Determining Feasibility Translating research into practice is a priority in clinical psychology. Frazier, Formoso, Birman and Atkins (2008) argued that community-based feasibility studies are essential to assess long-term practicality and sustainability of lab-validated research. There is a dearth of published literature addressing the successes and challenges of implementing and sustaining successful intervention programs in community settings. Fortunately, many researchers are working to fill the research gaps and entire issues of recent research journals have been dedicated to this subject (e.g., June 2008 issue of Clinical Psychology: Science and Practice dedicated to advocating for more community-based research and feasibility studies).

Glasgow, Lichtenstein, and Marcus (2003) summarized specific phases involved in translating efficacy research into clinical practice: hypothesis development, determining methodology, establishing efficacy, measuring effectiveness, and finally translating interventions into large-scale community programs. The authors cite the lack of articles evaluating the processes that occur once efficacy is established, and 
point to the scarcity of feasibility studies in community settings. The authors also provide a framework for successfully guiding research into practice referred to as REAIM: Reach, Efficacy or Effectiveness, Adoption, Implementation and Maintenance/Cost. The authors argue that many published (e.g., efficacy) studies employ these strategies but focus on narrowly defined samples in controlled settings, while community effectiveness studies focus on generalization and broad implementation. Thus, feasibility studies attempting to implement efficacious interventions in community settings fill a critical gap in the existing research.

The surgeon general released a report in 2000 entitled Children's Mental Health: Developing a National Action Plan, which outlined a vision for promoting childhood mental health, integrating all child health services, involving families in mental health care and developing support for mental health resources. The report also delineated eight specific goals for achieving this vision, including promoting public awareness, developing and implementing intervention services for children, improving the identification of mental health problems in children, eliminating sociodemographic disparities in mental health care for children, improving infrastructure, improving access, training providers, and monitoring mental health care services. These goals serve as guidelines for translating child development research into successful community intervention programs aimed at decreasing risks for later psychosocial problems (USPHS, 2000). Researchers are exploring innovative means for closing gaps in service by conducting small-scale feasibility studies.

Small-scale research studies are particularly valuable in pediatric psychology because of the limited evidence for program effectiveness in targeted pediatric samples. 
Additionally, feasibility studies are critical to laying the groundwork for large-scale intervention studies and their attention to small, important details can greatly inform later randomized-controlled trials (RCT) and program implementation efforts. For example, Kazak, Simms, Alderfer, Rourke, Crump, McClure, et al. (2005) established that an innovative intervention targeting anxiety and post-traumatic symptoms in families of children with newly diagnosed cancer was not only effective, but also decreased costs across the duration of the child's treatment such as those associated with individual psychotherapy appointments. Their intervention sample size was comprised of only 9 families. Similarly, Zeltzer, Tsao, Stelling, Power, Levy and Waterhouse (2002) discovered that children were highly receptive to receiving acupuncture and hypnosis to treat chronic pain and consequently reported improvements in functioning with a sample size of only 28 families. Finally, two pilot studies from the International Journal of Eating Disorders involved samples of only 7 and 4 participants) to evaluate a telephone-based intervention for binge eating disorder (Wells, Garvin, Dohm, and Striegel-Moore, 1997). The intervention resulted in decreases in binge eating behaviors and demonstrated the utility of an internet-based intervention (Zabinski, Wilfley, Pung, Winzelberg, Eldredge, \& Taylor, 2001).

\section{Current Study}

The current study is a feasibility study aimed at assessing the implementation of a validated parenting intervention program in a primary care clinic targeting Spanishspeaking Latino families. Additionally, the current study utilized a small sample size to pilot test the effect of the intervention on parent reports of parenting competency and practices and child behavior. Further, this study evaluated the feasibility of 
implementing the program and the recruiting and retaining Latino families. The program offered was the Chicago Parenting Program, an intervention specifically designed to be delivered in diverse settings with limited resources (Gross et al, 2003).

\section{Significance of Proposed Research}

The relationship between parenting practices and childhood behavior problems has been established in child development research (Bauer \& Webster-Stratton, 2006; Lochman, 2000; Yasui and Dishion, 2007). Further, the longer child behavior problems persist, the higher the risk becomes for CD, substance use and incarceration (Tremblay et al., 2004). Research on parenting interventions and treatments to prevent later child behavior problems had yielded promising results (Bauer \& Webster-Stratton, 2006), yet the majority of parenting interventions have established only efficacy (Glasgow, Lichtenstein, and Marcus, 2003) and have not yet evaluated the effectiveness of interventions with Latino, Spanish-speaking parents, let alone delivery in a primary care setting. This study evaluated the feasibility of implementing a previously validated (CPP; Gross et al., 2003) parenting intervention group in the MHMC Hispanic pediatric primary care clinic. This study also evaluated whether or not the primary care Spanish parenting groups were a desirable means for addressing the increasing disparities in Latino patients' access to quality mental health care.

In addition to providing mental health resources in the participants ‘ primary care clinics, the proposed intervention provided much-needed resources to parents in the language spoken by many at-risk families, by a provider of the same ethnicity. Only $1 \%$ of surveyed APA-member, licensed psychologists identified themselves as Latino, 
and there is little information available about the languages spoken by practicing psychologists (Bernal \& Castro, 1994). Therapy is likely to be most effective when the therapist speaks the same language as the client, yet few psychologists are Latinos and/or speak Spanish. Since there are limited bilingual providers, maximizing the impact of a single Spanish-speaking provider is important. Services provided in groups are an efficient way to use limited resources and providers, since more patients are served in a single session. Another advantage of this intervention was the culturally competent design, which accounted for cultural aspects of the targeted population, in accordance with recommendations by the Surgeon General's Report on providing mental health to ethnic minorities (USDHHS, 1999; Takeuchi, Sue, \& Yeh, 1995).

The current project delivered an intervention based on research on child development and prevention as well as cultural considerations that provided a realistic and attractive option for practicing clinicians. The current study was designed as an initial step in program evaluation and was aimed at guiding attempts to provide parenting groups in a county hospital environment. The outcomes of the proposed research will assist psychological providers in deciding whether or not the proposed format is a realistic means of addressing the increasing demand for bilingual parenting interventions. The current study satisfied several of the recommendations put forth by the Surgeon General to increase mental health resources, including implementation of prevention and treatment services by researching opportunities, evaluating existing interventions, assessing barriers and facilitators to the implementation of services, and determining cost-benefit ratios; and eliminating disparities by increasing the ease of 
patients' access to culturally competent, effective interventions and co-locating mental health services in highly utilized systems (e.g., primary care) (USPHS, 2000).

Yasui and Dishion (2007) advocated tailoring specific interventions to the individual needs of the children and families targeted as opposed to creating intervention programs aimed at specific ethnic minority groups. The current study was a hybrid of the two approaches, since individually tailored intervention efforts are difficult to develop if the individual needs are not well-understood. By pilot testing the CPP in a Puerto Rican population, we can begin to understand whether or not an intervention that has been validated in African-American and Mexican-American populations generalizes to Puerto Rican parents. Additionally, the model proposed by Yasui and Dishion (2007) is labor and time intensive and would not translate as well into a primary care intervention as a group-format intervention. By screening parents for child behavior concerns at well-child and primary care visits, the study also bypassed the complex and extended route of entry into mental health services described by Arcia et al. (2004).

Finally, this project served as a pilot study to inform future, larger-scale research efforts aimed at evaluating the ability of a behavioral parenting intervention to alleviate parent reports of childhood behavior problems and increase parenting efficacy and positive practices. The data collected from this investigation will provide a basis for future grant-funding efforts and will help to assess the costs and benefits of providing group-format interventions to parents of children with behavior problems. Unfortunately, there is a dearth of literature regarding the resources needed to 
implement such an intervention and realistic rates of reimbursement for services to this largely Medicaid population.

\section{Specific Research Aims}

The current project sought to evaluate the feasibility of an intervention to reduce disparities in Latino mental health/health care by addressing language issues, increasing community resources by making mental health more easily accessible, and ensuring coordination and comprehensive care within the clinic between medical and mental health providers. More specifically, the current research project aimed to evaluate the extent to which a group-based parenting intervention for child behavior problems is desirable, accepted, and effective in a Latino (predominantly Puerto Rican), Spanishspeaking primary care setting.

\section{Hypotheses}

Research on parenting interventions for behavioral concerns supports the efficacy of parenting groups as a means for service delivery across a variety of settings (Bauer \& Webster-Stratton, 2006). Based on previous research, we hypothesized that:

1. The CPP intervention would be a desirable option for addressing child behavior problems in an urban, primary care setting targeted at Latino families. Previous parenting program evaluations have demonstrated that parenting interventions are promising, and, when delivered correctly, self-sustaining (Bauer \& WebsterStratton, 2006). This hypothesis was tested by examining the number of parents reporting behavioral concerns and expressing interest in the intervention. 
2. The CPP intervention would be rated as acceptable and helpful by parents with behavioral concerns about their children, aged $2-8$ years. Acceptability was evaluated by noting how many enrolled parents attended at least $80 \%$ of the sessions, and helpfulness was examined by tracking weekly ratings recorded at the end of each weekly session.

3. Completion of the intervention would result in increased perceived parent competency and more effective parenting practices. Parent reports at baseline and post-treatment on two separate measures were compared to determine if there was a positive change in parent competency from pre to post intervention.

\section{Methodology}

\section{Participants}

The study took place at the Pediatric Hispanic Primary Care Clinic at MetroHealth Medical Center, a large, public, urban tertiary care health care network in Cleveland, Ohio that is affiliated with Case Western Reserve University School of Medicine. The bilingual clinic staff includes three pediatricians, two nurses, a medical assistant, an education advocate, and a psychological consultant. Additional support is provided by a legal services advocate. The clinic targets monolingual and bilingual Spanish speaking families and seeks to provide a comprehensive medical home for the families. Most of the clinic patients qualify for Medicaid and present with complex environmental, medical, and psychosocial stressors.

Parents were approached in the clinic rooms if they had one or more children between the ages of 2 and 8 years, were primarily Spanish speaking, and presented to 
the MHMC Hispanic pediatric clinic for medical services. Potential participants were not approached if all children in the family were younger than 24 months or older than 8 years and if Spanish was not their primary language. In order for participants to participate in the weekly intervention, they had to display a sixth grade reading level; therefore, potential participants who were unable to comprehend the recruitment materials were excluded from the intervention. Recruitment occurred for a period of one month prior to the first class of each of the three group sessions.

A total of 44 primary caregivers completed screening forms on their children during a Pediatric Hispanic Clinic appointment. Of these, 35 parents met inclusion criteria with reported concerns about their child's behavior and were invited to participate in the study. Twelve (34\% of the 35$)$ parents who endorsed behavioral concerns for their children declined participation in the intervention. Eight (23\%) parents did not participate because they could not be located after their visit (had moved or changed phone numbers) or indicated that they had child care problems.

Nine $(26 \%)$ mothers (mean age $=32.9, \mathrm{SD}=4.9)$ attended at least one of the 10 week intervention sessions, and 6 parents completed the intervention. All of the identified children in the families participating in the intervention were boys (mean age 6.1, SD 1.4). Seven participants identified Puerto Rico as their country of origin, and the highest level of education attained for the mothers ranged from fifth grade to some graduate school. Demographic information for the participants is summarized in Table 2.

Figure 1 visually represents the recruitment and intervention process. All parents of children 8 and under in the MHMC Pediatric Hispanic Clinic were given the 
Evaluacion De Los Padres Del Nivel Del Desarrollo, the Spanish translation of the Parents` Evaluation of Developmental Status (PEDS; Glascoe, 1997). The PEDS is a standardized and validated developmental screening instrument from birth to 8 years that asks parents whether or not they have concerns about their child's development in 10 areas, including speech, cognitive abilities, motor skills, behavior, socialization, and living skills. The PEDS has been shown to have moderate sensitivity (79\%) and specificity (80\%), and performs well compared to other developmental screening tools.

Parents who endorsed concerns about their children's behavior on the screener were approached by research staff and invited to participate in the intervention. Additionally, parents were asked to sign a consent form allowing the researchers to collect demographic information from their medical chart and contact them about the timing and location of the parenting groups. Parents were offered compensation for their time to complete forms and for participating in the intervention sessions (total compensation \$50), which was paid in two parts, \$25 at the baseline data collection and $\$ 25$ at the post-intervention data collection.

\section{Procedure}

After parents agreed to participate and provided informed consent they were assigned to one of three sets of 10-week sessions according to the timing of recruitment. Randomization did not occur since the study is feasibility based, and not focused on changes between groups. All groups occurred commenced within three weeks of identification/recruitment and all parents were provided with weekly reminder calls.

There were two major assessment points: baseline data collected at enrollment and post-treatment collected immediately following the intervention. All measures were 
given at both time points, with the exception of the Therapy Attitude Inventory (TAI; Eyberg, 1974), which was only given post-intervention. Baseline data collection was conducted by the study Principal Investigator (PI), while the post-intervention data collection was conducted by undergraduate research assistants who did not participate in the intervention sessions.

In addition to the two major assessment points, weekly intervention and satisfaction and helpfulness ratings were collected. Participants were reminded at each data collection point that all responses are confidential to decrease biased reporting. Post-intervention data were not collected for mothers who dropped out of the intervention prior to completing the sessions.

\section{Intervention}

The investigation utilized the CPP, a manualized behavioral parenting intervention intended to educate Spanish speaking parents about how to effectively manage their children's behavior through positive parenting practices. The intervention consisted of 10, 1-hour, therapist-led, weekly sessions focused on effective parenting strategies. See Table 3 for an overview of the CPP intervention components. The CPP is divided into three units: the value of parent attention (4 classes); how to use parent authority wisely (4 classes); and how to manage parent stress ( 2 classes). The units are intended to teach important behavioral principles and strategies, including childcentered time, using praise, encouragement, threats and consequences, active ignoring, positive reinforcement and problem-solving. Since the CPP was created as a culturally adapted Incredible Years curriculum, participants were shown brief videos with diverse 
families in vignettes demonstrating the methods presented in the program and followedup with group-wide discussion and weekly assignments.

The intervention sessions occurred on Saturday mornings and were conducted solely in Spanish by a clinical psychology doctoral student (project PI) with supervision by a licensed psychologist. As many as three parents/caregivers were allowed to attend any and all sessions, but only one parent/caregiver was included in data collection and was reimbursed for participation. There was no cost or insurance charges to the families for participation and all intervention sessions occurred in a conference room adjacent to the MHMC Hispanic Pediatric Primary Care clinic patient rooms. Breakfast was provided for parents at all meetings and childcare was provided by Child Life staff and research assistants at $\mathrm{MHMC}$ in order to address an established barrier to attendance. At the completion of the 10-week intervention, all participants who attended $>75 \%$ ( 8 out of 10 ) of sessions were given a certificate of completion.

To address treatment fidelity, the $\mathrm{PI} /$ therapist requested periodical email communication with the intervention developer to ensure any problems with the intervention were addressed. Fortunately, the email exchanges were mostly used to update the CPP developer on the progress of the groups and no problems arose.

\section{Measures}

In addition to a short questionnaire measure about family demographics (caregiver age, highest level of education attained, country of origin, total number of children, and marital status), measures included assessment of parent impressions of the intervention and child and family functioning, as detailed below. All measures were administered in Spanish (see Table 4 for a listing of measures and their properties). 


\section{Intervention Characteristics}

1. Feasibility: Acceptance and Satisfaction - The Therapy Attitude Inventory (TAI, Eyberg, 1974) is a 10-item scale used to measure a parent's perception of the impact of parent training. Parents are asked to indicate satisfaction with the training program on a 1 (dissatisfaction) to 5 (highest level of satisfaction) scale on questions examining changes in parent and child relationship, discipline, child behavior, compliance, personal and family functioning, and general feelings about the program. The scale produces scores from 10 (very dissatisfied) to 50 (consistently very satisfied). Internal validity of the TAI is 0.88 and the scale has been shown to identify treatment effects following parenting programs (Eyberg, 1993). The TAI has been translated into Spanish and used to evaluate parent satisfaction following Spanish-language parent training (Matos, Bauermeister, \& Bernal, 2009).

2. Parent Weekly Satisfaction Report - To document parents' impressions of weekly sessions, we ended each intervention session with a weekly likert-scale inventory asking about impressions of the session content, discussion, and principles. The inventory is provided with the CPP materials (Gross, 2003). Parents also completed this form following the final weekly session to provide an overall evaluation of satisfaction with the program.

\section{Child Functioning}

3. Child psychosocial problems - Parent reports of children's psychosocial problems were evaluated using the Cuestionario Sobre El Comportamiento De Ninos (CSCN), the Spanish translation of the Child Behavior Checklist (CBCL, 
Achenbach, 2001). The CBCL is a parent report questionnaire consisting of items pertaining to a wide range of child behavior problems; there are two forms of the measure, one for caregivers of children aged $1.5-5$ years and a second form for parents of children aged 6-18 years. Parents completed the questionnaire by rating the frequency of each behavior problem on a 3-point scale. The measure yields age-adjusted $\mathrm{T}$-scores (mean $\mathrm{T}=50, \mathrm{SD}=10)$ on Internalizing and Externalizing subscales and on a Total Problem scale; parent reported behaviors are also categorized as Normal $(\mathrm{T} \leq 64)$, Borderline Clinical $(65 \leq \mathrm{T} \leq 69)$ or Clinical $(\mathrm{T} \geq 70)$. For this study, T-scores for Externalizing, Internalizing, Total Problems, Attention Problems, and Aggressive Behaviors T-scores were used in analyses as baseline and post-intervention measures. The $\mathrm{CSCN}$ is commonly used in research with Latino populations, and Rubio-Stipec, Bird, Canino, and Gould (1990) provide internal consistency estimates for the CSCN based on a sample of Puerto Rican children aged 4-16 (see Table 4).

\section{$\underline{\text { Parent Functioning }}$}

4. Parenting competency -A Spanish translation of the Parenting Sense of Competence (PSOC; Johnston, \& Mash, 1989) scale, a 17-item measure utilizing 6-point Likert scales ranging from "strongly disagree" to "strongly disagree," was used to assess parenting self-esteem. The PSOC provides Total, Satisfaction, and Efficacy scale scores and higher scores are associated with higher parenting selfesteem. While clinical cutoffs are not provided by the authors of the scale, several studies have provided the norms of their samples. Gilmore and Cuskelly's (2008) community sample had an average Satisfaction total of $22.72(\mathrm{SD}=5.8)$ and an 
Efficacy total of $22.03(\mathrm{SD}=4.1)$. Ohan, Leung and Johnston's (2000) sample norms were slightly higher, with mothers of 5-6 year old boys reporting an average Satisfaction total of $36.38(\mathrm{SD}=6.9)$ and mothers of 7-9 year old boys an average of $38.79(\mathrm{SD}=6.9)$. Mothers of 5-6 year old boys reported an average Efficacy score of $21.63(\mathrm{SD}=6.5)$ and mothers of 7-9 year old boys had an average Efficacy score of $26.88(\mathrm{SD}=6.6)$.

Original reliability estimates indicate the Total, Satisfaction and Efficacy scales have good internal consistency, $0.79,0.75$ and 0.76 , respectively (Johnston \& Mash, 1989). Ohan, Leung, and Johnston (2000) evaluated the factor structure and concurrent validity of the PSOC and found high internal consistency values ( 0.80 for both the Satisfaction and Efficacy scales in mothers) and external validity when compared to measures of child behavior, rearing practices, intrafamily relationships and correlations between parents. The Spanish version of the PSOC has been used with clinical populations (Gerdes \& Schneider, 2009).

5. Parenting practices - To assess parenting practices, we utilized a Spanish translation of the Parenting Scale (PART; Arnold, O`Leary, Wolff, \& Acker, 1993), a 30-item scale that assessed discipline practices and provides a total score in addition to three subscales: laxness, overreactivity, and verbosity. The verbosity scale is often interpreted with caution, or not included in analyses, due to poor psychometric support (Harvey, Danforth, Ulaszek, \& Eberhardt, 2001; Helfenbaum-Kun \& Ortiz, 2007; Steele, Nesbitt-Daly, Daniel, \& Forehand, 2005). See Table 4 for reliability estimates. Parents are provided with situations requiring a choice in discipline strategies and asked to rank their parenting practices on a 7- 
point likert scale, with 'mistakes' on one end of the scale and the 'effective strategies' on the other end. The validity of the scale was established by Arnold et al. (1993) by comparing parent responses to observed parent and child behavior in both clinical and non-clinical groups. The PARTS has been translated into Spanish and used with Hispanic populations (Helfenbaum-Kun \& Ortiz, 2007).

The total score provides an overall estimate of undesirable parenting practices. The laxness scale examines parents' methods for enforcing rules and providing consequences and consists of 11 items. The overreactivity scale contains 10 items and examines the frequency of parents' expression of anger, meanness and irritability. Finally, the verbosity scale assesses parents' use of talking in managing children and consists of 7 items. Higher scores on any of the subscales indicate more undesirable parenting practices in that area. Clinical cutoffs are not provided by the authors of the scale, but Steele et al. (2005) evaluated the factor structure of the scale in a low-income African American sample of children roughly 9-13 years of age and reported an average Laxness scale score of 12.4 $(\mathrm{SD}=4.8)$ and Overreactivity score of $20.41(\mathrm{SD}=5.5)$ for parents of the boys in the study, and an average Laxness scale score of $11.88(\mathrm{SD}=4.8)$ and Overreactivity score of $22.35(\mathrm{SD}=4.85)$ for parents living in urban neighborhoods. However, direct comparisons with our sample cannot be made due to Steele et al.'s (2005) lack of Verbosity norms and the removal of several questions from the Laxness and Overreactivity scales.

6. Parent Depression: The Center for Epidemiologic Studies Depression Scale (CES-D; Radloff, 1977), a 20-item measure assessing depressive symptomatology 
on a 0 (rarely) to 3 (most or all of the time) scale was administered to assess for maternal depression, which is associated with low levels of parenting efficacy (Gross, Conrad, Fogg, \& Wothke, 2007). A score of 16 or above is used to indicate an individual with potential clinical depression (Radloff, 1977). A cutoff score of 16 is suggested to identify depression, though research indicates that his may overestimate depression in non-clinical samples (Santor, Zuroff, Ramsay, Cervantes, \& Palacios, 1995). The Spanish version of the CES-D has been used in many research studies (Bromberger, Harlow, Avis, Kravitz,\& Cordal, 2004; Guarnaccia, Angel, \& Worobey, 1989) Research conducted on Latino populations indicate that the established cutoff scores for depression may not be generalizable to Latino populations due to Latinos' tendency to collapse affective and somatic symptoms of depression, which creates a difference in the factor structure of the measure (Guarnaccia et al., 1989). For the purposes of this study, we will not be collapsing the CES-D into factors and will be utilizing the total score.

\section{$\underline{\text { Physician Feedback }}$}

The MHMC Pediatric Hispanic Clinic pediatricians were surveyed about their knowledge and opinions regarding the parenting classes using a brief questionnaire created for this study. Questions included whether or not the physicians were aware the groups were occurring in the clinic, if any of their patients participated, if the groups were recommended to any patients, what the physicians knew about the groups, if the physicians heard any feedback, whether the physicians would be more likely to screen for behavior problems if an on-site service were available, and what the physicians believed was important to the success of parenting groups in the clinic. 


\section{Data Analysis Plan}

A combination of quantitative and descriptive data analyses were conducted to describe the data collected and test the study hypotheses.

The first hypothesis, related to the practicality of implementing the intervention, was evaluated by recording trends in recruitment, including the percentage of total target sample parents endorsed behavioral concerns, number of those parents agreed to participate, and number of participating families who attended at least one session. Data regarding the costs and logistical needs (e.g., overall cost, space, personnel) necessary to implement the proposed intervention were also collected.

The second hypothesis, related to the acceptability and helpfulness of the intervention, was evaluated based on descriptive information, including the mean and modal number of sessions attended by parents. Parent reports of intervention helpfulness were collapsed into a general rating of the overall intervention, as well as broken down by intervention session.

The final hypothesis, related to treatment effectiveness, was examined by conducting t-tests on the pre-post data (CBCL, PSOC, and the PARTS). This method follows the methodology applied by Zeltzer, Tsao, Stelling, Powers, Levy, and Waterhouse (2002) in their feasibility study of the effectiveness of a hypnosis/acupuncture intervention in children with chronic pain. 


\section{Results}

\section{Recruitment}

A total of 44 parents were screened about concerns regarding their children's behavior. The screening occurred during a waiting period in the clinic room during the child's visit in the MHMC Pediatric Hispanic Clinic. Physicians were aware of the presence of the research assistant, but research assistants left the room during the actual medical visit and physicians were not made aware of the parents ${ }^{\text {}}$ decisions to enroll in the intervention to maintain participant confidentiality. Of the 44 parents, $9(20.5 \%)$ reported having no behavioral concerns about their children on the PEDS screener, while 35 parents $(79.5 \%)$ endorsed behavioral concerns.

Of the 35 parents endorsing behavioral concerns, 12 parents $(27 \%)$ indicated to the recruiting research staff member that they were not interested in the intervention. The most common reason given for refusal was (4 parents) a preference for individual outpatient services (see Table 5 for a summary of reasons provided). Twenty-three parents $(52 \%)$ expressed interest in the group intervention. Following the recruitment phase, several parents who had expressed interest in the intervention did not attend any sessions. One of the most common reasons was logistical: 10 parents confirmed planning to attend the first session, but when child care was unexpectedly unavailable the day before the session was to begin, only 4 parents were able to attend the intervention sessions. This response was given despite parent notification of the availability of child care at MHMC. Six parents who failed to attend the sessions following enrollment reported losing interest in the program. Six additional parents who enrolled could not be contacted by research staff base on the contact information 
provided. See Table 6 for a summary of reasons for non-participation following enrollment.

Nine parents attended at least one session of the group parenting intervention. These nine parents constituted $20 \%$ of parents approached in clinic, $26 \%$ of parents who endorsed behavioral concerns, and 39\% of parents interested in intervention. A total of 6 parents completed the intervention, which is $14 \%$ of the total sample, $17 \%$ of the parents who endorsed behavior problems, $27 \%$ of the parents who expressed an initial interest in the sessions, and $67 \%$ of parents who attended at least one session. See Table 7 for a summary of parent responses and percentage of each subcategory.

A total of three sessions were held. Four parents enrolled in the first session and two completed the program, three parents enrolled in the second session and two completed it, and two parents enrolled in and completed the third session.

2. Intervention Satisfaction and Child and Parent Functioning Outcomes

Program Satisfaction - The Treatment Attitude Inventory (TAI, Eyberg, 1974) was used to assess parents' perceptions of the helpfulness of the program. The average TAI score was 45.2 of a possible 50, which indicates that parents were satisfied with the parenting groups.

Parent ratings on the weekly satisfaction questionnaires indicated that satisfaction with the program was consistently high. No parent rated a single session's components as less than helpful' and most rated most components as being _very helpful,' especially those parents who eventually completed the program. See Table 8 for a summary of weekly and final program evaluations. Parents expressed appreciation for the opportunity for group discussions involving other parents, written summaries of 
each session's main points, and the vignettes used to illustrate each class's principles. Table 9 provides weekly satisfaction ratings by participant. The satisfaction ratings demonstrate that all parents were satisfied with the classes but that those who attend at least three sessions were the most likely to complete the intervention.

Behavioral Problems - Child behavior and general functioning was measured using the Spanish translation of the CBCL (Achenbach, 2001). Table 10 lists these scores by participant; two participants' scores were not included in analyses due to too many missing items and a resultant lack of interpretable scale scores. As a result, seven scores were included in the baseline analyses and five scores were included in all baseline and post-intervention analyses. Six of the seven parents endorsed at least Borderline functioning in at least one CBCL scale and 5/7 mothers endorsed Clinical functioning in at least one CBCL scale at baseline.

There were no significant differences between parents who completed and did not complete the intervention on baseline CBCL Total, Externalizing, Internalizing, and Aggression scores . However, there appeared to be a trend toward significance for the CBCL Attention subscale $(\mathrm{t}=-0.20, \mathrm{p}=0.54)$, with the intervention completers reporting a higher average $\mathrm{T}$-score $($ mean $=63.2, \mathrm{SD}=4.8)$ than the non-completers $($ mean $=62.0, \mathrm{SD}=12.7)$

The mean baseline Total Problem T-score was 66.9 ( $\mathrm{SD}=9.9)$, which was in the borderline clinical range. The average baseline T-score for Total problems for participants who completed the program was $68.6(\mathrm{SD}=8.8)$, compared to a postintervention score of $60.8(\mathrm{SD}=14.3)$; there were no significant differences between 
baseline and post-intervention scores $(t=2.06, p=0.11)$, but all parents reported fewer problems on the Total Problems scale after post-intervention than they did at baseline.

The average baseline T-score for Externalizing problems was 65.1 $(\mathrm{SD}=11.2)$, which was in the borderline clinical range. The average baseline T-score for Externalizing problems for participants who completed the program was $65.2(\mathrm{SD}=$ 11.3), compared to a post-intervention score of $60.4(\mathrm{SD}=11.4)$. There were no significant differences between baseline and post-intervention scores $(t=1.47, p=0.22)$, however only one mother reported worse outcomes in her child's Externalizing Problems scores from baseline to post-intervention.

The average baseline T-score for Internalizing problems was $64.6(\mathrm{SD}=10.5)$, which is not a clinically significant elevation. The average baseline T-score for Internalizing problems for participants who completed the program was $67.8(\mathrm{SD}=$ 7.4), compared to a post-intervention score of $57.6(\mathrm{SD}=15.4)$. There were no significant differences between baseline and post-intervention scores $(\mathrm{t}=2.36, \mathrm{p}=$ 0.08), however there was a trend towards significance and no parent reported worsening of their child's Internalizing Problems scores.

The average baseline T-score for Attention Problems was 62.9 $(\mathrm{SD}=6.5)$, which was not in the borderline clinical range. The average baseline T-score for Attention Problems for participants who completed the program was $63.2(\mathrm{SD}=4.8)$, compared to a post-intervention score of $62.2(\mathrm{SD}=7.6)$. There were no significant differences between baseline and post-intervention scores and thus no evidence that the parenting groups were associated with reduced attention problems in their children $(\mathrm{t}=$ $0.36, \mathrm{p}=0.74)$. 
The average baseline T-score for Aggression problems was $67.0(\mathrm{SD}=12.5)$, which falls in the borderline clinical range. The average baseline T-score for Aggression problems for participants who completed the program was $66.0(\mathrm{SD}=9.6)$, compared to a post-intervention score of $61.6(\mathrm{SD}=7.7)$. There were no significant differences between baseline and post-intervention scores and thus no evidence that the parenting groups were associated with reduced aggression problems in their children $(\mathrm{t}$ $=1.26, \mathrm{p}=0.28)$.

Additional, nonparametric group comparisons using Mann-Whitney, Wilcoxon Signed Ranks and McNemar tests failed to reveal any differences between the baseline scores of completers and non-completers or between baseline and post-intervention scores.

Parenting Self-Esteem - The average baseline PSOC total score was 65.9 (SD = 11.6) out of a possible 96. The average baseline Satisfaction score was 32.5 (SD = 11.7) out of a possible 54. The average Efficacy score was $33.4(\mathrm{SD}=4.6)$ out of a possible 42. The average baseline scores on the PSOC for parents who did not complete the intervention did not differ significantly from those parents who did on any scale. There was a significant difference between parents' baseline and post-intervention scores on the PSOC Satisfaction scale, indicating that the parenting groups were associated with improved parenting satisfaction $(\mathrm{t}=-3.48, \mathrm{p}=0.04)$, but there were no significant differences between baseline and post-intervention scores on the Total $(\mathrm{t}=$ $1.53, \mathrm{p}=0.20)$ or Efficacy $(\mathrm{t}=-0.56, \mathrm{p}=0.61)$ scales. See Table 11 for a summary of PSOC scores by participant. 
Parenting Practices - The average baseline PARTS total score was 102.4 (SD = 13.7) out of a possible 210. The average baseline Laxness score was $31.7(\mathrm{SD}=9.97)$ out of a possible 77. The average Overreactivity score was $33.4(\mathrm{SD}=6.3)$ out of a possible 70, and the average baseline Verbosity score was a $29.8(\mathrm{SD}=5.8)$ out of a possible 49. The average baseline PARTS scores for parents who did not complete the intervention did not differ significantly from those parents who did. There were no significant differences between baseline and post-intervention scores, however, all but one mother reported a worse outcome on the Laxness scale. See Table 12 for a summary of PARTS scores by participant.

Parental Depression - The CES-D (Radloff, 1979) was used to assess maternal depression. The average baseline score was $36.38(\mathrm{SD}=8.52)$, and all mothers obtained scores well above 16, the recommended cutoff for prediction of clinical levels of depression. The average baseline score for participants who completed the program was $37.0(\mathrm{SD}=9.46)$, compared to a post-intervention score of $32.0(\mathrm{SD}=6.9)$. Despite there being no significant difference between baseline and post-intervention CES-D scores $(\mathrm{t}=2.36, \mathrm{p}=0.078)$, there was a trend toward lower scores post-intervention, indicating the parenting groups may be associated with reduced depressive symptomatology in the mothers. The average baseline depression score for parents who did not complete the intervention did not differ significantly from those parents who did $(t=-.025, p=0.70)$. See Table 13 for a summary of CES-D scores and by participant.

Physician feedback indicated that physicians were aware and supportive of the parenting groups, but generally did not recommend the groups to parents. Physicians' responses implied an enhanced motivation to screen for behavior problems if an 
established on-site service were available. Physicians indicated that providing child care and having access to parent feedback about the groups would be important to the ultimate success of the groups. See Table 14 for a summary of physician responses.

\section{Discussion}

This study examined the feasibility of, and barriers to, implementing a Spanish parenting intervention in a large, public county hospital's pediatric primary care clinic specifically treating Spanish-speaking families. Ultimately, we sought to determine whether primary care-based Spanish parenting groups were a feasible means for addressing the increasing disparities in Latino patients ${ }^{6}$ access to quality mental health care. We posited that the group intervention would be a desirable option for addressing child behavior problems. The results revealed that $80 \%$ of all parents approached endorsed concerns about their children's behavior and that $66 \%$ of parents who endorsed these concerns expressed interest in the parenting intervention. We also predicted that the intervention would be rated as acceptable and helpful. The results demonstrated that parents who participated in the intervention uniformly rated the components (e.g., vignettes, group discussion, format) as helpful, useful, and satisfying. Additionally, all parents who completed the intervention reported that they would highly recommend the program to other parents. Our third hypothesis predicted that the intervention would result in decreased child behavior problems, increased perceived parenting competency and more effective parenting practices. Consistent with this hypothesis, comparisons of the baseline and post-intervention questionnaire data revealed improved ratings by all parents who completed the ratings in children's Total and Internalizing Problems on the 
CBCL (Achenbach, 2001), parenting satisfaction as measured by the Parenting Practices Scale (Arnold et al., 1993), and depression as measured by the CES-D (Radloff, 1977). For most mothers there were also baseline to post-intervention improvements in Externalizing and Aggression Problems as measured by the CBCL and parenting laxness and overreactivity as measured by the PSOC (Johnston \& Mash, 1989).

Despite the small sample size and resultant limited power, statistical analyses revealed significant improvements in parenting satisfaction as measured by the PSOC between baseline and post-intervention scores and trends toward improvements in CBCL Internalizing Problems and maternal depression scores. Results are promising considering Latino children's increased risk for serious behavior problems (Coatsworth et al., 2002) and parenting interventions' consistent efficacy in alleviating behavior problems in children (Bauer \& Webster-Stratton, 2006; Lochman, 2000). Additionally, these results are in the direction of research indicating that that higher maternal depression is related to lower levels of self-reported parenting competency (Gross et al., 2007), although correlations were not assessed due to the small sample size.

In addition to demonstrating the effectiveness of the intervention, this study provides information about parents ${ }^{6}$ behavioral concerns and openness to group-format intervention. Twenty percent of all parents approached participated in the parenting groups and $67 \%$ of the parents who attended at least one session completed the intervention. Parent reports indicate that the program was seen as useful, and highlighted several particularly helpful aspects of the intervention. First, parents consistently appreciated the vignettes, and one mother reported enjoying _watching how 
to do it right instead of being told what I was doing wrong.' Second, parents valued the weekly handouts, which reviewed the principles of the session and provided examples of how to implement the strategies. One mother reportedly kept her handouts on the refrigerator to remind her how to handle difficult situations. Third, parents regularly commented on the value of the group discussion. The parents would often discuss their own attempts at implementing parenting techniques and share ideas about how to adapt the techniques depending on child temperament or share advice about unsuccessful strategies. The mothers would inquire about each others ' children's functioning during the previous week and celebrate milestones. One on occasion, a mother used a reward system to encourage her 7 year-old son to sleep in his own bed for the first time. When this mother returned the following week and reported success after a single night, the other mothers in the group and the therapist congratulated the mother for her success. The mothers would often share similar stories about their own upbringings and their

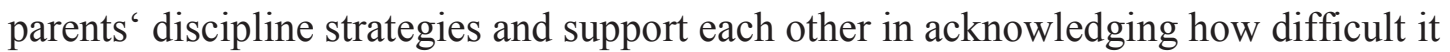
could be acculturating into a new society and set of social values. Additionally, parents expressed appreciation for the presence of the therapist, who provided examples of other successful parents' ideas and novel strategies when parents had difficulty with particular principles. Parents indicated that weekly classes were not overwhelming and the length of each class (roughly one hour) was acceptable. Finally, parents who brought children to the groups reportedly appreciated the availability of child care and indicated attendance would not be possible without the service.

In addition to the praise for the groups, parents provided constructive criticisms of the CPP curriculum. Primarily, the mothers reported noticing that many of the 
vignettes involved children under the age of 4-5 years interacting with both their mothers and fathers. The mothers indicated that they wanted more scenes utilizing elementary school-age children and more single parents. Several parents in the study also identified a need for parenting strategies aimed at their older children and inquired about available services. These comments suggest the need to consider parenting interventions for adolescents as well as children in the development of a parenting curriculum. A program aimed at parents of adolescents might focus on such concepts as monitoring, adolescent development, and recognizing and addressing risky behaviors.

Taken together, the results indicated that the urban, primary care parenting groups were desirable, useful, and effective for parents endorsing behavioral concerns about their children. These findings also demonstrated the potential benefit of implementing established interventions in trusted settings for specific populations that are at increased risk for not receiving needed mental health services. Despite these benefits and identification of many non-participating families who expressed concerns about their children's behavior, there were several barriers to successful implementation of the group intervention for parents.

One barrier was the occurrence of hospital-wide changes that had detrimental effects on several components of the proposed intervention. The most significant challenge to the program was the unanticipated withdrawal of child care services by MHMC's Child Life department. Despite agreeing to provide child-care during the Saturday morning classes, a concern about liability for caring for the study children in the Child Life playroom during off-clinic hours resulted in Child Life staff rescinding 
their offer. Because this decision was made the day before the first set of classes was to begin, last-minute phone calls had to be made to parents to inform them that child care would not be available as promised. As a consequence, 7 of the 10 parents who had agreed to participate declined further involvement. By the second week of the intervention, the liability issues had been resolved and child care was restored, but only one additional parent joined the parenting group.

A second setback occurred when MHMC experienced financial strain and eliminated many support positions, including all but two Child Life employees. This change made it unfeasible to provide child care on the weekends because the two remaining Child Life employees were working longer hours to cover the employees who had been terminated. As a result, the child care was provided in an empty waiting room by research assistants trained as volunteers at local children's hospital instead of a hospital playroom equipped with computers, blocks, books, and other play materials. In addition to the elimination of Child Life positions, two bilingual pediatricians left MHMC during the project, which reduced the number of days and patients available to be screened. Unfortunately, financial hardships are difficult to predict and therefore solutions are not readily available.

Another challenge was inclement weather. Several of the mothers walked from nearby neighborhoods or rode 2-3 buses to the hospital. During the winter sessions, several classes had to be cancelled or postponed when the parents had a difficult time making it safely to the hospital. One way to meet this challenge would be to plan for make-up dates for missed sessions. 
Similarly challenging were scheduling conflicts with the parents. Saturday appeared to be a good choice for all but three parents who worked on Saturdays. It may be important to offer groups at different days of the week so that more parents can attend. In addition to make-up sessions and varying the days that the intervention is offered, it may be helpful to have a rotating curriculum so parents could begin at a convenient time and have opportunities to make up intervention sessions that they were unable to attend. The model of weekly, successive curriculum is well-established and validated, but successively offered, or "rotating" programs may help in recruiting parents who would otherwise have to wait several weeks or months for the next class to begin.

Another challenge was the project's lack of an integration with primary pediatric care in recruitment of families and in delivery of the intervention. The current study was not intended as a model of integrated services but was instead focused on the feasibility of delivering the intervention to clinic patients in the clinic space. Feedback following the groups revealed that while the physicians were aware of the parenting groups, most did not discuss the groups with parents because they were not involved in identifying families for services. However, the physicians' responses indicated interest in parent feedback regarding the groups and a desire to utilize psychosocial services established in the clinic. The relative success of the current project highlights the benefits of primary care mental health interventions (Table 1), including provision of mental health services in a clinic setting that is credible and familiar to the families. Including pediatricians and clinic staff in future recruitment and retention efforts and requesting their endorsement would likely help sustain clinic-based parenting groups. 
Recruitment and retention was particularly challenging. Despite the many parents who expressed interest in the intervention, maintaining contact with the parents after recruitment was difficult due to outdated contact information, even in the span of several days or weeks. One solution is to ask the participants to provide at least two phone numbers and an address so that reminder phone calls and a letter can be sent to remind parents of the group sessions. Weekly reminder calls are also important in ensuring that parents attend the first few weeks of classes.

One final challenge was the scarcity of established measures validated on Latino and/or Puerto Rican populations. Only one measure (CES-D) had separate norms for specific Latino populations (Guarnaccia et al., 1989), but these norms were published more than 20 years ago. Several measures were piloted but not included in the final project due to the mothers' difficulty understanding the forms. For instance, one measure assessing children's problem behaviors required mothers to report on the level of the behavior as well as whether or not the behaviors were currently a problem almost all mothers provided answers for only one section at a time, invalidating the measure.

Several qualitative observations are also noteworthy. First, the trends in attendance and barriers mirror those encountered by the Hispanic Clinic staff more generally. Although reminder calls are an integral part of the Hispanic Clinic's success, many parents do not have working phone numbers and children's physicians often have difficulties contacting parents for follow-up appointments similar to those experienced in this study. 
A second observation is the relevance of distinguishing between single and twoparent households. The graphs of the outcome measures indicate that all single mothers reported improvements in most areas, with the exception of children's attention and parenting efficacy and verbosity. While all three married mothers in the program commented on its usefulness, two expressed a desire to encourage their spouse attendance at the sessions. One husband attended three classes with his wife but he did not complete any study measures.

A further observation was the bond that occurred between the Child Life workers and the children in the first intervention session. During the first two weeks of the session, parents expressed guilt in having to wake up their children on a Saturday morning in order to attend the classes. By the third and fourth week, the children were waking the mothers up to ensure that the family would make it to the hospital in time for the classes. The children enjoyed the Child Life playroom and the activities that the Child Life staff created for them, including making Valentine's Day boxes, cards, and cookies, decorating Easter eggs, and building cities with an extensive collection of blocks. This dynamic was not present when the volunteers (who were not experienced Child Life professionals) provided child care.

A final observation was the sense of accomplishment conveyed by the mothers who successfully employed strategies learned during the group sessions, including proper use of reward systems, logical consequences, and conflict resolution strategies. The mothers often began the sessions believing that they were familiar with the principle for the week but would then express surprise at how little they knew about 
implementing a specific strategy after viewing vignettes regarding the use of methods such as positive attention, time out, ignoring.

One major determinant of program sustainability is the potential for reimbursement of program costs. The cost of implementing parenting group classes depends on the level of service provided and facility resources. In general, group therapy services such as the CPP are reimbursable through third party payers such as Medicaid as long as the child has a diagnosable condition. If there is no diagnosable condition (for example, the child does not meet criteria for a DSM (APA, 2000) diagnosis), payment for sessions from third party payers may be problematic and require family or alternate sources of funding. Many parenting groups are considered psychoeducational and may not qualify for reimbursement as therapeutic intervention services (Siegmann \& Bower, 1995).

Lobbying for funding for these services may be one means for obtaining an appropriate level of support. The National Institutes of Health's (NIH) Substance Abuse and Mental Health Services Administration (SAMHSA) published a resource kit on family psychoeducation as an evidence-based practice in providing services for individuals with mental illness (USDHHS, 2003). According to SAMHSA's (2003) toolkit, the savings per dollar of family psychoeducation (FPE) can be $\$ 34$ for each dollar spent. Considering Foster et al.'s (2005) estimation that treating ODD can exceed $\$ 13,000$ and CD can cost over $\$ 26,000$ annually, advocating for FPE for early childhood behavior problems in imperative and could save hospitals and Medicaid organizations thousands of dollars per child. Information in SAMHSA's toolkit (2003) 
also documents the fact that many state Medicaid organizations provide funds and/or reimbursements for FPE programs.

One of the benefits of delivering the parenting groups as a psychoeducation/prevention effort is that children with predisposing/risk factors for later DBD and CD can be treated before more serious behavior problems emerge. A second benefit is that a preventative approach precludes the need to diagnose children and thus avoids possible stigma associated with a formal diagnosis. Instead of visiting multiple offices within the hospital (primary care clinic, psychology intake and/or social work department), parents could be seen in the familiar space of the primary care clinic.

This study was intended to assess program feasibility as a means to inform the design of subsequent evaluations of the effectiveness of programs targeted to Latino populations receiving primary medical services within urban, public-care settings. The findings established program feasibility and highlighted barriers that would need to be addressed prior to implementation of more formal tests of treatment effectiveness (see Table 15 for a summary of lessons learned from the study outcomes). The next step in this line of research is to conduct a randomized control trial to determine if group sessions are superior to waiting list control condition and comparable to individualized outpatient services in reducing child behavior problems and improving parenting practices. Other important research goals are to determine if improvements made in the parenting groups are sustained after several months and/or years and to compare the effectiveness of the programs aimed at preventing behavior problems with programs designed as secondary/tertiary interventions. 
The current study provided much-needed Spanish resources to Spanish-speaking parents presenting to a primary care clinic who endorsed behavioral concerns about their young children. The intervention was delivered by a bilingual, Latino provider. In accordance with recommendations by the Surgeon General's Report on providing mental health services to ethnic minorities (USDHHS, 1999; Takeuchi et al., 1995), the intervention was provided in Spanish and thus addressed an important barrier common to the targeted population. The study also applied knowledge about child development, culture, and prevention in designing and implementing an intervention that was practical for Latino parents and that could be readily incorporated into a primary care setting. The outcomes from this study corroborate Cunningham, Bremner and Boyle's (1995) finding that Latino parents are receptive to group therapy settings and will be used to inform future efforts in implementing group-format bilingual parenting interventions. 
Appendix

Table 1. Benefits of Primary Care Mental Health Intervention for Latinos

\begin{tabular}{|c|c|}
\hline $\begin{array}{l}\text { Traditional Challenges and Barriers to } \\
\text { Receiving Mental Health Services }\end{array}$ & $\begin{array}{l}\text { Solutions Offered by Primary Care } \\
\text { Psychological Interventions }\end{array}$ \\
\hline $\begin{array}{l}\text { 1. Traditionally negative patient attitudes } \\
\text { toward mental health providers. }\end{array}$ & $\begin{array}{l}\text { 1. Providers belong to a credible } \\
\text { organization. }\end{array}$ \\
\hline $\begin{array}{l}\text { 2. Lack of simple access to mental health } \\
\text { services. }\end{array}$ & $\begin{array}{l}\text { 2. Co-location of services helps patients } \\
\text { and parents access initial mental health } \\
\text { resources and helps mental health } \\
\text { providers in reaching a larger audience. }\end{array}$ \\
\hline $\begin{array}{l}\text { 3. Difficulty navigating mental health } \\
\text { system. }\end{array}$ & $\begin{array}{l}\text { 3. Mental health providers are based in } \\
\text { familiar medical clinic, allowing for } \\
\text { continuity of care. }\end{array}$ \\
\hline $\begin{array}{l}\text { 4. Effort to seek out mental health services } \\
\text { outweighs perceived benefits of service. }\end{array}$ & $\begin{array}{l}\text { 4. Co-located mental health providers can } \\
\text { answer mental health service-related } \\
\text { questions and help patients and parents } \\
\text { develop a realistic idea about how mental } \\
\text { health services could help. }\end{array}$ \\
\hline $\begin{array}{l}\text { 5. Lack of follow-through with } \\
\text { appointments due to lapses in time } \\
\text { between referrals and appointment. }\end{array}$ & $\begin{array}{l}\text { 5. Initial contact with mental health } \\
\text { provider in primary care clinic provides } \\
\text { unique continuity of care and may increase } \\
\text { parent accountability for services. }\end{array}$ \\
\hline 6. Long waiting lists to receive services. & $\begin{array}{l}\text { 6. Interventions provided in clinics are } \\
\text { open to multiple parents on a set schedule. }\end{array}$ \\
\hline
\end{tabular}

Adapted from Stancin, Perrin and Ramirez (2009) 
Table 2. Demographics of intervention sample

\begin{tabular}{|l|c|c|c|c|c|c|}
\hline ID* & $\begin{array}{c}\text { Country of } \\
\text { Origin }\end{array}$ & Age & $\begin{array}{c}\text { Number of } \\
\text { children }\end{array}$ & Marital status & $\begin{array}{c}\text { Age of } \\
\text { child** }\end{array}$ & $\begin{array}{c}\text { Highest } \\
\text { level of ed } \\
\text { attained }\end{array}$ \\
\hline 1 & $\begin{array}{c}\text { South } \\
\text { American }\end{array}$ & 33 & 4 & Married & 8 & $5^{\text {th }}$ grade \\
\hline 2 & Puerto Rican & 31 & 1 & Widowed & 6 & $\begin{array}{c}\text { Graduate } \\
\text { school }\end{array}$ \\
\hline 3 & Puerto Rican & 30 & Not provided & Never Married & 7 & $11^{\text {th }}$ grade \\
\hline 4 & Puerto Rican & 31 & 4 & Divorced & 7 & Some college \\
\hline 5 & Puerto Rican & 23 & 2 & Separated & 4 & $12^{\text {th }}$ grade \\
\hline 6 & Puerto Rican & 36 & 3 & Divorced & 6 & College \\
\hline 7 & Puerto Rican & 40 & 2 & Separated & 6 & $9^{\text {th }}$ grade \\
\hline 8 & South & 37 & 2 & Married & 7 & $12^{\text {th }}$ grade \\
\hline 9 & Puerto Rican & 35 & 3 & Married & 4 & Some college \\
\hline Mean & & $32.9(4.9)$ & $2.6(1.1)$ & & $6.1(1.4)$ & \\
\hline
\end{tabular}

*all mothers, **all male children 
Table 3. Content of Chicago Parenting Program

\begin{tabular}{|c|c|c|}
\hline Unit & Session/Subunit No: Title & Main Strategies Presented \\
\hline \multirow{4}{*}{$\begin{array}{l}\text { 1: The Value of Your } \\
\text { Attention }\end{array}$} & 1/1: Child-Centered Time & $\begin{array}{l}\text { Principles of child-centered } \\
\text { physical and pretend play. }\end{array}$ \\
\hline & $\begin{array}{l}\text { 2/2: Family Routines and } \\
\text { Traditions }\end{array}$ & $\begin{array}{l}\text { Using family to increase } \\
\text { children's confidence, teach } \\
\text { values and instill a sense of } \\
\text { belonging and control }\end{array}$ \\
\hline & $\begin{array}{l}\text { 3/3: Praise and } \\
\text { Encouragement }\end{array}$ & $\begin{array}{l}\text { Principle: -flyou want to see } \\
\text { the behavior again, give it } \\
\text { your attention" }\end{array}$ \\
\hline & $\begin{array}{l}\text { 4/4: Using Rewards for } \\
\text { Challenging Behaviors }\end{array}$ & $\begin{array}{l}\text { Being clear, simple, and } \\
\text { logical with rewards. }\end{array}$ \\
\hline \multirow{4}{*}{$\begin{array}{l}\text { 2: Using Your Authority } \\
\text { Wisely }\end{array}$} & $\begin{array}{l}\text { 5/1: Say What You Mean and } \\
\text { Mean What You Say }\end{array}$ & $\begin{array}{l}\text { Being clear, direct, positive } \\
\text { and respectful with } \\
\text { commands. }\end{array}$ \\
\hline & $\begin{array}{l}\text { 6/2: Threats and } \\
\text { Consequences }\end{array}$ & $\begin{array}{l}\text { Using -fithen" and } \\
\text {-whenthen" statements, } \\
\text { logical and appropriate } \\
\text { consequences, and follow- } \\
\text { through. }\end{array}$ \\
\hline & 7/3: Ignore and Distract & $\begin{array}{l}\text { Principle: -flyou do NOT } \\
\text { want to see the behavior } \\
\text { again, do NOT give it your } \\
\text { attention." }\end{array}$ \\
\hline & 8/4: Using Time-Outs & $\begin{array}{l}\text { Explaining time-out before it } \\
\text { is used; not attending to child } \\
\text { in time-out; age appropriate } \\
\text { times; and ending on a } \\
\text { positive note once child } \\
\text { complies. }\end{array}$ \\
\hline \multirow[b]{2}{*}{ 3: Managing Your Stress } & 9/1: Reducing Your Stress & $\begin{array}{l}\text { Taking a parent time-out, } \\
\text { breathing, counting, relaxing, } \\
\text { and reframing. }\end{array}$ \\
\hline & 10/2: Problem-Solving & $\begin{array}{l}\text { Facilitating communication: } \\
\text { schedule time to talk, define } \\
\text { problems, list solutions, make } \\
\text { a plan and end on positive } \\
\text { note. }\end{array}$ \\
\hline
\end{tabular}


Table 4. Psychometric properties of outcome measures

\begin{tabular}{|c|c|c|}
\hline Measure & Construct & Reliability Estimates \\
\hline $\begin{array}{l}\text { Cuestionario Sobre El } \\
\text { Comportamiento De Ninos, } \\
\text { Externalizing Score (CSCN) } \\
\text { [Spanish translation of Child } \\
\text { Behavior Checklist (CBCL)] }\end{array}$ & $\begin{array}{l}\text { Parent report of child } \\
\text { characteristics }\end{array}$ & $\begin{array}{l}\text { Alpha }=.89-94^{1} \\
\text { Test-retest }=\text { N/A } \\
\text { Sensitivity }=\text { N/A } \\
\text { Specificity }=\text { N/A }\end{array}$ \\
\hline $\begin{array}{l}\text { Parenting Practices } \\
\text { (PARTS), Total Score }\end{array}$ & $\begin{array}{l}\text { Use and frequency of specific } \\
\text { parenting practices }\end{array}$ & $\begin{array}{l}\text { Alpha }^{2} \\
\text { Total }=.84 \\
\text { Laxness }=.83 \\
\text { Overreactivity }=.82 \\
\text { Verbosity }=.63 \\
\text { Test-retest }^{2} \\
\text { Total }=.84 \\
\text { Laxness }=.83 \\
\text { Overreactivity }=.82 \\
\text { Verbosity }=.79 \\
\text { Sensitivity }=\text { N/A } \\
\text { Specificity }=\text { N/A }\end{array}$ \\
\hline $\begin{array}{l}\text { Cuestionario Sobre El } \\
\text { Comportamiento De Ninos } \\
\text { (CSCN) } \\
\text { [Spanish translation of Parents` } \\
\text { Evaluation of Developmental } \\
\text { Status (PEDS)]^ }\end{array}$ & $\begin{array}{l}\text { Parental concerns about } \\
\text { development and behavior }\end{array}$ & $\begin{array}{l}\text { Alpha }=.81^{3} \\
\text { Test-retest }=.88 \\
\text { Sensitivity }=.75 \\
\text { Specificity }=.74\end{array}$ \\
\hline $\begin{array}{l}\text { Parenting Sense of Competence } \\
\text { (PSOC), Total Score }{ }^{\wedge}\end{array}$ & Parenting competence & $\begin{array}{l}\text { Alpha }^{4} \\
\text { Satisfaction }=.75 \\
\text { Efficacy }=.76 \\
\text { Test-retest }=\text { N/A } \\
\text { Sensitivity }=\text { N/A } \\
\text { Specificity }=\text { N/A }\end{array}$ \\
\hline $\begin{array}{l}\text { Center for Epidemiological } \\
\text { Studies Depression Scale (CES- } \\
\text { D) }\end{array}$ & Parental depression & $\begin{array}{l}\text { Alpha }= \\
\text { Test-retest }\end{array}$ \\
\hline Therapy Attitude Inventory^ & $\begin{array}{l}\text { Parental satisfaction with } \\
\text { parenting program. }\end{array}$ & $\begin{array}{l}\text { Alpha }=.88^{5} \\
\text { Test-retest }=\text { N/A } \\
\text { Sensitivity }=\text { N/A } \\
\text { Specificity }=\text { N/A }\end{array}$ \\
\hline
\end{tabular}

N/A - Not available; ${ }^{\wedge}$ Separate Spanish norms not available

${ }^{1}$ Rubio-Stipec, Bird, Canino, \& Gould (1990), only range provided

${ }^{2}$ Arnold, O‘Leary, Wolff, \& Acker (1993)

${ }^{3}$ Glascoe (1997)

${ }^{4}$ Johnston \& Mash (1989)

${ }^{5}$ Matos, Bauermeister, \& Bernal (2009) 
Table 5. Parent-reported reasons for refusal to participate in program $(\mathrm{N}=12)$

\begin{tabular}{|l|l|}
\hline Reason for Lack of Interest in Program & $\begin{array}{l}\text { Number of parents } \\
\text { reporting }\end{array}$ \\
\hline Wanted individual outpatient services & 4 \\
\hline Works on Saturday & 3 \\
\hline Already receiving services through local organization & 1 \\
\hline Church & 1 \\
\hline Lack of transportation & 1 \\
\hline Saturday is only day with kids & 1 \\
\hline Wanted to weigh options' & 1 \\
\hline
\end{tabular}


Table 6. Reasons parents did not attend sessions despite expressing interest $(\mathrm{N}=14)$

\begin{tabular}{|l|l|}
\hline Reason for Lack of Attendance & \\
\hline No childcare at initial session & 6 \\
\hline Not able to contact parent following recruitment & 6 \\
\hline No transportation & 1 \\
\hline Too many children for childcare & 1 \\
\hline
\end{tabular}


Table 7. Breakdown by percentages of parent interest/disinterest/attendance

\begin{tabular}{|c|c|c|c|c|}
\hline Parent Responses & $\begin{array}{l}\text { Total } \\
(\mathrm{N}=44)\end{array}$ & $\begin{array}{c}\text { Positive PEDS } \\
\text { screeners } \\
(\mathrm{N}=35)\end{array}$ & $\begin{array}{c}\text { Parents } \\
\text { interested in } \\
\text { the intervention } \\
(\mathrm{N}=23)\end{array}$ & $\begin{array}{l}\text { Parents attending } \\
\text { at least one session } \\
\qquad(\mathrm{N}=9)\end{array}$ \\
\hline $\begin{array}{l}\text { No behavioral Concerns } \\
(\mathrm{N}=9)\end{array}$ & $20.5 \%$ & & & \\
\hline Behavioral concerns $(\mathrm{N}=35)$ & $79.5 \%$ & & & \\
\hline $\begin{array}{l}\text { Behavioral concerns, but not } \\
\text { interested in intervention } \\
(\mathrm{N}=12)\end{array}$ & $27 \%$ & $34 \%$ & & \\
\hline $\begin{array}{l}\text { Behavioral concerns, } \\
\text { interested in the intervention } \\
(\mathrm{N}=23)\end{array}$ & $52 \%$ & $66 \%$ & & \\
\hline $\begin{array}{l}\text { Interested in intervention but } \\
\text { did not attend any sessions } \\
(\mathrm{N}=14)\end{array}$ & $52 \%$ & $40 \%$ & $61 \%$ & \\
\hline Attended at least one session & $20 \%$ & $26 \%$ & $39 \%$ & \\
\hline Completed intervention & $14 \%$ & $17 \%$ & $27 \%$ & $67 \%$ \\
\hline
\end{tabular}


Table 8. Summary of weekly and final program evaluations

\begin{tabular}{|l|c|c|c|}
\hline ID & $\begin{array}{c}\text { Weekly } \\
\text { Average } \\
\text { (of 20) }\end{array}$ & $\begin{array}{c}\text { TAI* } \\
\text { (of 50) }\end{array}$ & $\begin{array}{c}\text { Total } \\
\text { Sessions } \\
\text { attended }\end{array}$ \\
\hline 1 & 20 & 45 & 10 \\
\hline 2 & 19 & 50 & 10 \\
\hline 3 & 17 & - & 6 \\
\hline 4 & 17 & - & 2 \\
\hline 5 & - & - & 1 \\
\hline 6 & 17 & 46 & 10 \\
\hline 7 & 19.4 & 44 & 10 \\
\hline 8 & 20 & 41 & 10 \\
\hline 9 & 19.3 & 45 & 8 \\
\hline Mean & 18.6 & 45.2 & 7.4 \\
\hline
\end{tabular}

$*$ TAI $=$ Therapy Attitude Inventory 
Table 9. Summary of weekly satisfaction ratings (out of 20 possible points)

\begin{tabular}{|l|c|c|c|c|c|c|c|c|c|}
\hline ID & $\begin{array}{c}\text { Week 2 } \\
\text { Routines }\end{array}$ & $\begin{array}{c}\text { Week 3 } \\
\text { Praise }\end{array}$ & $\begin{array}{c}\text { Week 4 } \\
\text { Rewards }\end{array}$ & $\begin{array}{c}\text { Week 5 } \\
\text { Being } \\
\text { Consistent }\end{array}$ & $\begin{array}{c}\text { Week 6 } \\
\text { Conseq- } \\
\text { uences }\end{array}$ & $\begin{array}{c}\text { Week 7 } \\
\text { Ignoring }\end{array}$ & $\begin{array}{c}\text { Week 8 } \\
\text { Time- } \\
\text { Out }\end{array}$ & $\begin{array}{c}\text { Week 9 } \\
\text { Reducing } \\
\text { Stress }\end{array}$ & $\begin{array}{c}\text { Week 10 } \\
\text { Problem } \\
\text { Solving }\end{array}$ \\
\hline 1 & 20 & 20 & 20 & 20 & 20 & 20 & 20 & 20 & 20 \\
\hline 2 & 20 & 20 & 20 & 19 & 20 & 20 & 20 & 20 & 20 \\
\hline 3 & 18 & - & 18 & 17 & 16 & 16 & - & - & - \\
\hline 4 & 17 & - & - & - & - & - & - & - & - \\
\hline 5 & - & - & - & - & - & - & - & - & - \\
\hline 6 & 15 & 20 & 17 & 16 & 18 & 19 & 18 & 18 & 15 \\
\hline 7 & 18 & 17 & 20 & 20 & 20 & 20 & 20 & 20 & 20 \\
\hline 8 & 20 & 20 & 20 & 20 & 20 & 20 & 20 & 20 & 20 \\
\hline 9 & 15 & 20 & 20 & - & 20 & - & 20 & 20 & 20 \\
\hline Mean & 17.9 & 19.5 & 19.3 & 18.7 & 19 & 19.2 & 19.7 & 19.7 & 19.2 \\
\hline
\end{tabular}


Table 10. Baseline/post-intervention Child Behavior CheckList $(\mathrm{CBCL})$ data $(\mathrm{N}=9)$

\begin{tabular}{|c|c|c|c|c|c|c|c|c|c|c|}
\hline & \multicolumn{10}{|c|}{ CBCL T-scores } \\
\hline & \multicolumn{2}{|c|}{$\begin{array}{c}\text { Total } \\
\text { Problems }\end{array}$} & \multicolumn{2}{|c|}{ Externalizing } & \multicolumn{2}{|c|}{ Internalizing } & \multicolumn{2}{|c|}{ Attention } & \multicolumn{2}{|c|}{ Aggression } \\
\hline ID & Pre & Post & Pre & Post & Pre & Post & Pre & Post & Pre & Post \\
\hline 1 & $\mathrm{n} / \mathrm{s}$ & $\mathrm{n} / \mathrm{s}$ & $\mathrm{n} / \mathrm{s}$ & $\mathrm{n} / \mathrm{s}$ & $\mathrm{n} / \mathrm{s}$ & $\mathrm{n} / \mathrm{s}$ & $\mathrm{n} / \mathrm{s}$ & $\mathrm{n} / \mathrm{s}$ & $\mathrm{n} / \mathrm{s}$ & $\mathrm{n} / \mathrm{s}$ \\
\hline 2 & 53 & 42 & 46 & 44 & 57 & 41 & $66^{*}$ & 55 & 50 & 50 \\
\hline 3 & $73^{* *}$ & - & $76^{* *}$ & - & $68^{* *}$ & - & 71 & - & 86 & - \\
\hline 4 & $\mathrm{n} / \mathrm{s}$ & - & $\mathrm{n} / \mathrm{s}$ & - & $\mathrm{n} / \mathrm{s}$ & - & $\mathrm{n} / \mathrm{s}$ & - & $\mathrm{n} / \mathrm{s}$ & - \\
\hline 5 & 52 & - & 54 & - & 45 & - & 53 & - & 53 & - \\
\hline 6 & $70^{* *}$ & 49 & $72^{* *}$ & 56 & $65^{\circ}$ & 41 & 55 & 53 & $76^{*}$ & 59 \\
\hline 7 & $73^{* *}$ & $68^{*}$ & $69^{* *}$ & 61 & $71^{* *}$ & 65* & 64 & $67^{* *}$ & $69^{* *}$ & 62 \\
\hline 8 & $73^{* *}$ & 71" & $65^{*}$ & $67^{* *}$ & $77^{* *}$ & $72 * *$ & 64 & $69^{* *}$ & $67^{\circ}$ & $69^{* *}$ \\
\hline 9 & $74^{* *}$ & $74^{\prime \prime}$ & $74^{\prime \prime \prime}$ & $74^{* *}$ & $69^{* * *}$ & $69^{* *}$ & $67^{* *}$ & $67^{* * *}$ & $68^{* * *}$ & $68^{* \prime}$ \\
\hline $\begin{array}{l}\text { Mean and } \\
\text { (SD) for } \\
\text { Sample }\end{array}$ & $\begin{array}{l}66.86 \\
(9.9) \\
\end{array}$ & & $\begin{array}{l}65.14 \\
(11.2)\end{array}$ & & $\begin{array}{l}64.57 \\
(10.5) \\
\end{array}$ & & $\begin{array}{l}62.86 \\
(\underline{6.5)}\end{array}$ & & $\begin{array}{r}67.0 \\
(12.5)\end{array}$ & \\
\hline $\begin{array}{l}\text { Mean and } \\
\text { (SD) for } \\
\text { Completers }\end{array}$ & $\begin{array}{l}68.60 \\
(\underline{8.9)}\end{array}$ & $\begin{array}{c}\mathbf{6 0 . 8} \\
(14.3) \\
\end{array}$ & $\begin{array}{c}65.2 \\
(\underline{11.3})\end{array}$ & $\begin{array}{r}60.4 \\
(11.4) \\
\end{array}$ & $\begin{array}{l}67.8 \\
(7.4)\end{array}$ & $\begin{array}{c}57.6 \\
(15.4)\end{array}$ & $\begin{array}{l}63.2 \\
(4.8)\end{array}$ & $\begin{array}{l}62.2 \\
(7.6) \\
\end{array}$ & $\begin{array}{l}66.0 \\
(\underline{9.6})\end{array}$ & $\begin{array}{l}\mathbf{6 1 . 6} \\
(\underline{7.7)} \\
\end{array}$ \\
\hline
\end{tabular}

- parent did not complete outcome survey $\mathrm{n} / \mathrm{s}$ - measure not scorable

${ }^{+}$No significant differences between baseline and post-intervention scores *indicates Borderline Clinically significant score **indicates Clinically significant score 
Table 11. Baseline/post-intervention Parenting Sense of Competency (PSOC) scores (N $=9$ )

\begin{tabular}{|c|c|c|c|c|c|c|}
\hline & \multicolumn{6}{|c|}{ PSOC Scale Scores* } \\
\hline & \multicolumn{2}{|c|}{ Total } & \multicolumn{2}{|c|}{ Satisfaction } & \multicolumn{2}{|c|}{ Efficacy } \\
\hline ID & Pre & Post & Pre & Post & Pre & Post \\
\hline 1 & $\mathrm{n} / \mathrm{s}$ & $\mathrm{n} / \mathrm{s}$ & $\mathrm{n} / \mathrm{s}$ & $\mathrm{n} / \mathrm{s}$ & $\mathrm{n} / \mathrm{s}$ & $\mathrm{n} / \mathrm{s}$ \\
\hline 2 & 80 & 80 & 41 & 48 & 39 & 32 \\
\hline 3 & 55 & - & 14 & - & 41 & - \\
\hline 4 & 84 & - & 49 & - & 35 & - \\
\hline 5 & 66 & - & 38 & - & 28 & - \\
\hline 6 & 72 & 87 & 42 & 50 & 30 & 37 \\
\hline 7 & 58 & 78 & 27 & 36 & 31 & 42 \\
\hline 8 & 58 & 57 & 25 & 26 & 33 & 31 \\
\hline 9 & 54 & 54 & 24 & 24 & 30 & 30 \\
\hline $\begin{array}{l}\text { Mean and } \\
\text { (SD) for } \\
\text { Sample }\end{array}$ & $\begin{array}{c}65.9 \\
(\underline{11.6)} \\
\end{array}$ & & $\begin{array}{c}32.5 \\
(11.7)\end{array}$ & & $\begin{array}{l}33.4 \\
(\underline{4.6})\end{array}$ & \\
\hline $\begin{array}{l}\text { Mean and } \\
\text { (SD) for } \\
\text { Completers }\end{array}$ & $\begin{array}{c}64.4 \\
(\underline{11.1})\end{array}$ & $\begin{array}{c}71.2 \\
(\underline{14.8})\end{array}$ & $\begin{array}{l}31.8 \\
(\underline{8.9})\end{array}$ & $\begin{array}{c}36.8 * * \\
(\underline{12.0})\end{array}$ & $\begin{array}{l}32.6 \\
(\underline{3.8})\end{array}$ & $\begin{array}{l}34.4 \\
(\underline{5.0})\end{array}$ \\
\hline
\end{tabular}

- parent did not complete outcome survey $\mathrm{n} / \mathrm{s}$ - measure not scorable

*Higher scores indicate more desirable outcomes

${ }^{* *}$ Significant differences between baseline and post-intervention scores $(\mathrm{p}<0.05)$ 
Table 12. Baseline/post-intervention Parenting Scale (PARTS) data $(\mathrm{N}=9)$

\begin{tabular}{|c|c|c|c|c|c|c|c|c|}
\hline & \multicolumn{8}{|c|}{ Parenting Practices Scale Scores* } \\
\hline & \multicolumn{2}{|c|}{ Total Score } & \multicolumn{2}{|c|}{ Laxness } & \multicolumn{2}{|c|}{ Overreactivity } & \multicolumn{2}{|c|}{ Verbosity } \\
\hline & Pre & Post & Pre & Post & Pre & Post & Pre & Post \\
\hline 1 & 103 & 112 & 36 & 38 & 31 & 43 & 31 & 27 \\
\hline 2 & 76 & 63 & 17 & 10 & 21 & 11 & 21 & 26 \\
\hline 3 & 104 & - & 37 & - & 34 & - & 26 & - \\
\hline 4 & 108 & - & 24 & - & 38 & - & 41 & - \\
\hline 5 & 122 & - & 48 & - & 41 & - & 24 & - \\
\hline 6 & 87 & 53 & 25 & 19 & 28 & 14 & 30 & 18 \\
\hline 7 & 114 & 79 & 43 & 21 & 35 & 18 & 33 & 26 \\
\hline 8 & 105 & 104 & 27 & 20 & 40 & 36 & 29 & 36 \\
\hline 9 & 103 & 102 & 28 & 28 & 33 & 32 & 33 & 33 \\
\hline $\begin{array}{l}\text { Mean and } \\
(\underline{\text { SD) }} \text { for } \\
\text { Total } \\
\text { Sample }\end{array}$ & $\begin{array}{l}102.4 \\
(\underline{13.7})\end{array}$ & & $\begin{array}{c}31.7 \\
(10.0)\end{array}$ & & $\begin{array}{l}33.4 \\
(\underline{6.3})\end{array}$ & & $\begin{array}{l}29.8 \\
(\underline{5.8})\end{array}$ & \\
\hline $\begin{array}{l}\text { Mean and } \\
\text { (SD) for } \\
\text { Completers }\end{array}$ & $\begin{array}{l}100.8 \\
(\underline{15.0})\end{array}$ & $\begin{array}{c}88.3 \\
(\underline{30.0})\end{array}$ & $\begin{array}{l}31.3 \\
(\underline{9.8})\end{array}$ & $\begin{array}{c}24.7 \\
(\underline{11.7})\end{array}$ & $\begin{array}{l}31.3 \\
(\underline{6.5})\end{array}$ & $\begin{array}{c}25.8 \\
(\underline{13.2})\end{array}$ & $\begin{array}{l}30.2 \\
(\underline{5.0})\end{array}$ & $\begin{array}{l}28.3 \\
(\underline{6.4})\end{array}$ \\
\hline
\end{tabular}

*missing scores were removed from pre and post analysis so the scores were comparable across data collection points

- parent did not complete outcome survey

$\mathrm{n} / \mathrm{s}$ - measure not scorable

${ }^{+}$No significant differences between baseline and post-intervention scores 
Table 13. Baseline/post-intervention Center for Epidemiological Studies Depression scale $(\mathrm{CES}-\mathrm{D})$ data $(\mathrm{N}=9)$

\begin{tabular}{|l|c|c|}
\hline ID & \multicolumn{2}{|c|}{$\begin{array}{c}\text { CES-D } \\
\text { Scores }\end{array}$} \\
\hline & Pre & Post \\
\hline 1 & $\mathrm{n} / \mathrm{s}$ & 69 \\
\hline 2 & 40 & $\mathbf{3 1}$ \\
\hline 3 & 45 & - \\
\hline 4 & 29 & - \\
\hline 5 & 32 & - \\
\hline 6 & 32 & $\mathbf{3 0}$ \\
\hline 7 & 45 & $\mathbf{3 4}$ \\
\hline 8 & 45 & $\mathbf{4 2}$ \\
\hline 9 & 23 & 23 \\
\hline $\begin{array}{l}\text { Mean and } \\
(\text { SD) for }\end{array}$ & 36.38 & \\
$\begin{array}{l}\text { Total } \\
\text { Sample }\end{array}$ & $\underline{8.5})$ & \\
\hline $\begin{array}{l}\text { Mean and } \\
\text { (SD) for } \\
\text { Completers }\end{array}$ & $\begin{array}{l}37.0 \\
(\underline{9.5})\end{array}$ & $\begin{array}{l}\mathbf{3 2 . 0} \\
(\underline{\mathbf{6 . 9}})\end{array}$ \\
\hline
\end{tabular}

- parent did not complete outcome survey

$\mathrm{n} / \mathrm{s}$ - measure not scorable

${ }^{+}$No significant differences between baseline and post-intervention scores 
Table 14. Hispanic clinic staff feedback regarding intervention

\begin{tabular}{|c|c|c|c|}
\hline Question: & Yes & No & Open ended \\
\hline $\begin{array}{l}\text { Aware of parenting groups } \\
\text { in clinic? }\end{array}$ & 4 & 0 & \\
\hline $\begin{array}{l}\text { What do you know about } \\
\text { groups? }\end{array}$ & & & $\begin{array}{l}\text {-Parenting skills for } \\
\text { younger mothers } \\
\text {-That they were being run }\end{array}$ \\
\hline $\begin{array}{l}\text { Any of your patients } \\
\text { participate? }\end{array}$ & 3 & 1 & \\
\hline $\begin{array}{l}\text { Did you recommend to } \\
\text { any? }\end{array}$ & 2 & 2 & \\
\hline Did you hear feedback? & 2 & 2 & $\begin{array}{l}\text {-Very interesting. They } \\
\text { need more of these classes }\end{array}$ \\
\hline $\begin{array}{l}\text { Would you recommend } \\
\text { groups in future? }\end{array}$ & 4 & 0 & \\
\hline $\begin{array}{l}\text { Would you be more likely } \\
\text { to screen if you knew you } \\
\text { had an on-site service } \\
\text { referral? }\end{array}$ & 4 & 0 & \\
\hline $\begin{array}{l}\text { What do you think is } \\
\text { important to success of } \\
\text { groups? }\end{array}$ & & & $\begin{array}{l}\text {-Know results of parent } \\
\text { feedback } \\
\text {-Child care } \\
\text {-Sustainability }\end{array}$ \\
\hline
\end{tabular}


Table 15. Lessons learned from feasibility study

\begin{tabular}{|c|c|}
\hline Challenges to overcome: & Solutions: \\
\hline $\begin{array}{l}\text { Inability to contact parents after } \\
\text { recruitment stage }\end{array}$ & $\begin{array}{l}\text { Obtain multiple points of contact } \\
\text { information, including two phone } \\
\text { numbers and an address to send a } \\
\text { reminder letter }\end{array}$ \\
\hline Parent scheduling conflicts & Be prepared to provide make up classes \\
\hline Child care is necessary & $\begin{array}{l}\text { Consider hospital-trained volunteers if } \\
\text { unable to pay for child care }\end{array}$ \\
\hline \multicolumn{2}{|l|}{ Relationships valued by families: } \\
\hline \multicolumn{2}{|c|}{ The bond between the Child Life child care providers and the children } \\
\hline \multicolumn{2}{|c|}{ Discussion with and support received from other parents in the groups } \\
\hline Novel ideas from and shared suc & th the therapist \\
\hline
\end{tabular}


Figure 1. Recruitment and Intervention

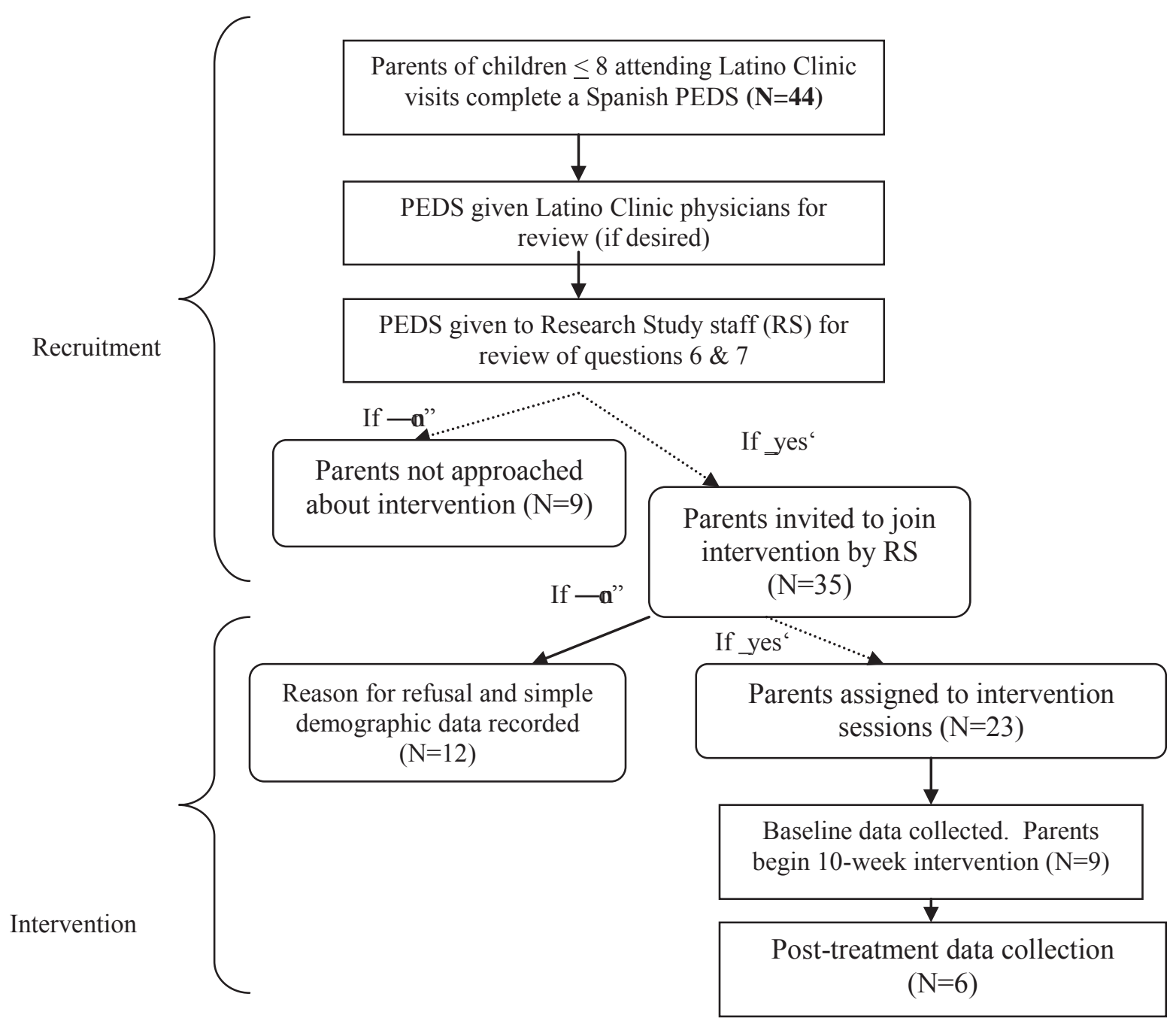


Figure 2. CBCL Total baseline (pre) and post-intervention T-scores

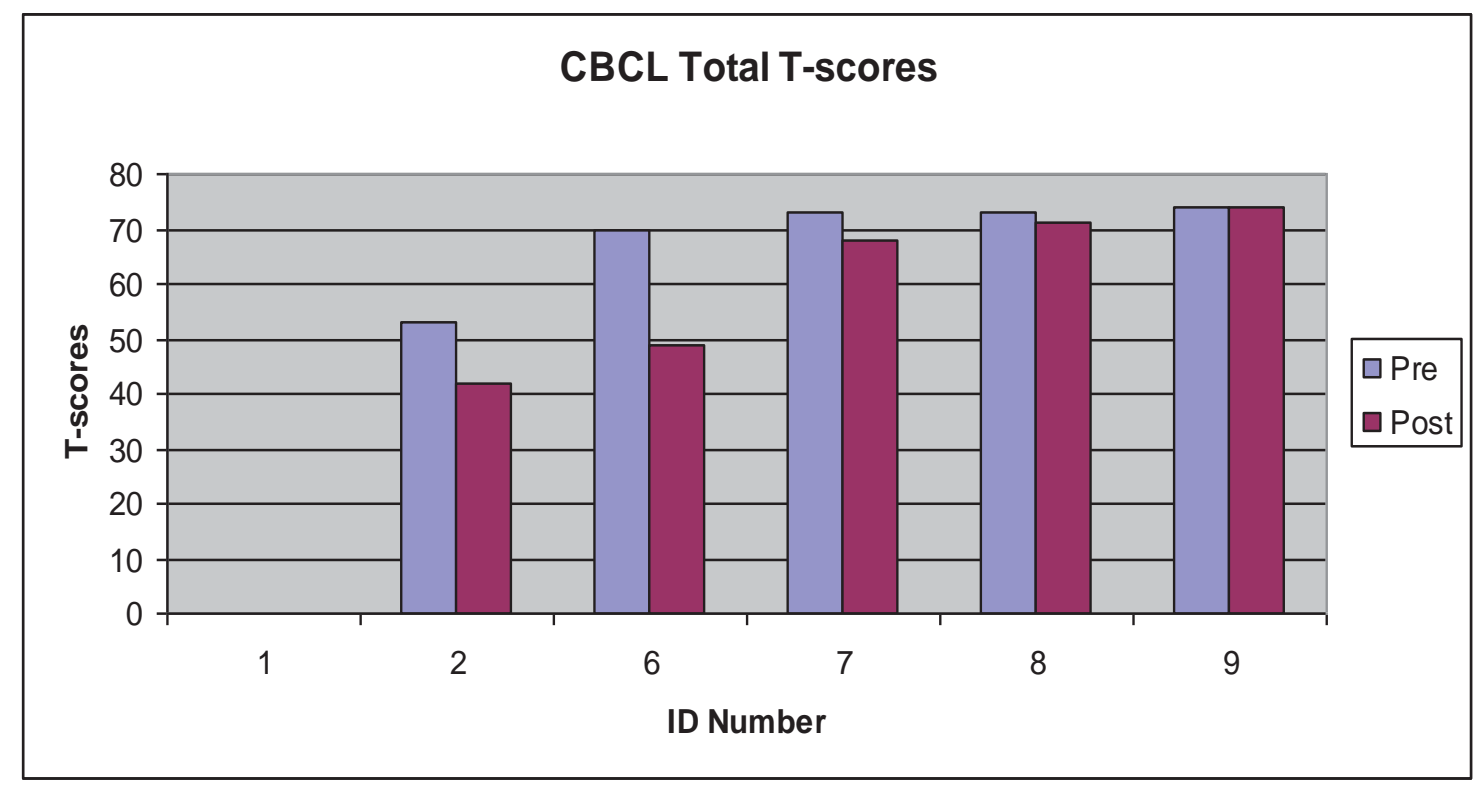


Figure 3. CBCL Externalizing baseline (pre) and post-intervention T-scores

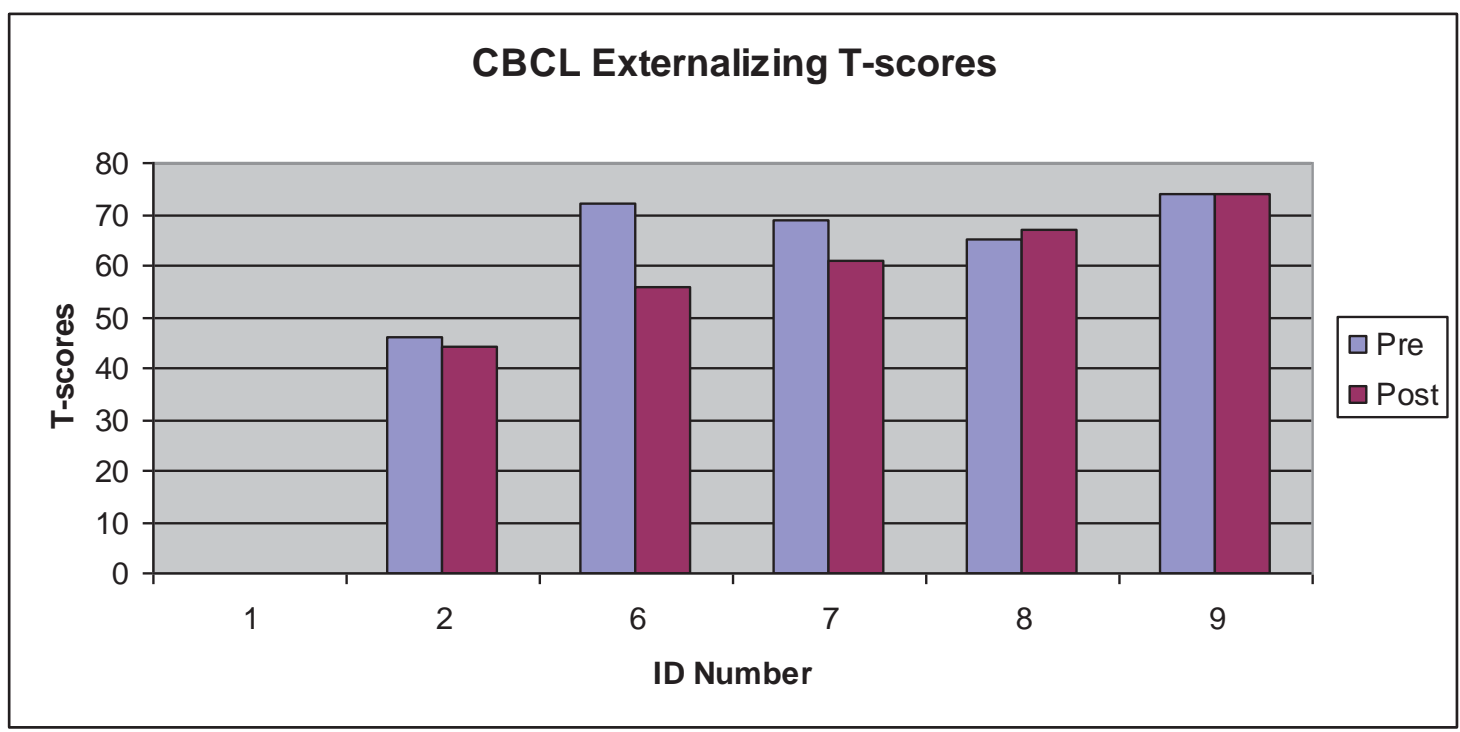


Figure 4. CBCL Internalizing baseline (pre) and post-intervention T-scores

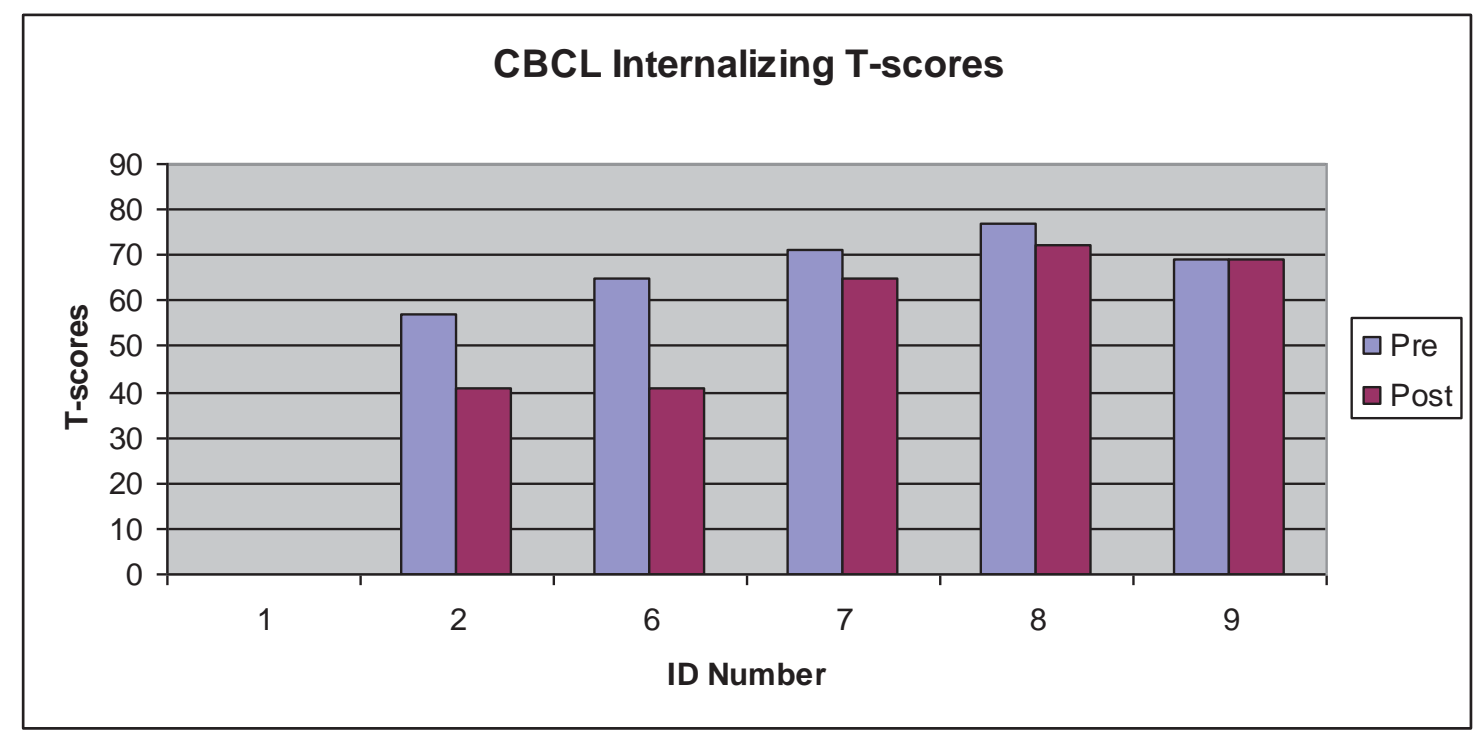


Figure 5. CBCL Attention baseline (pre) and post-intervention T-scores

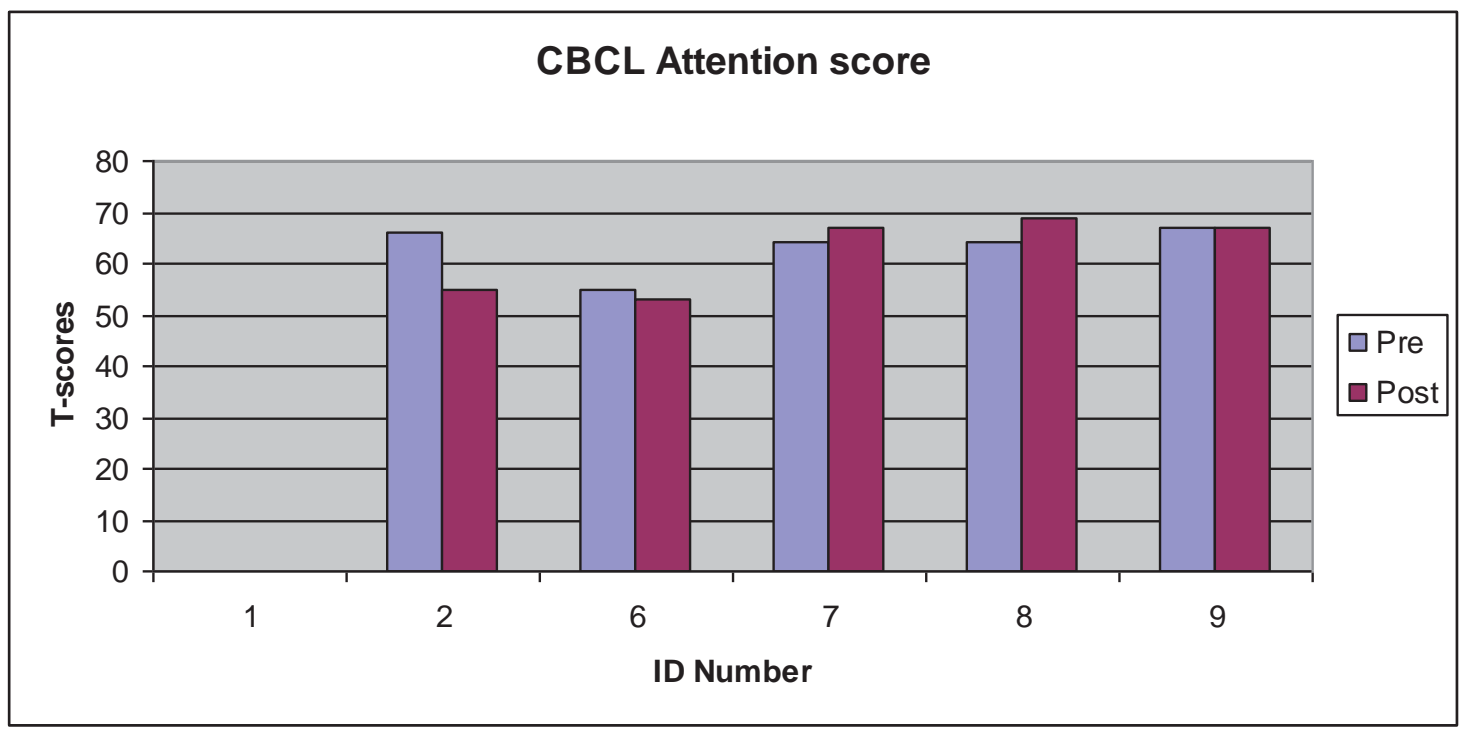


Figure 6. CBCL Attention baseline (pre) and post-intervention T-scores

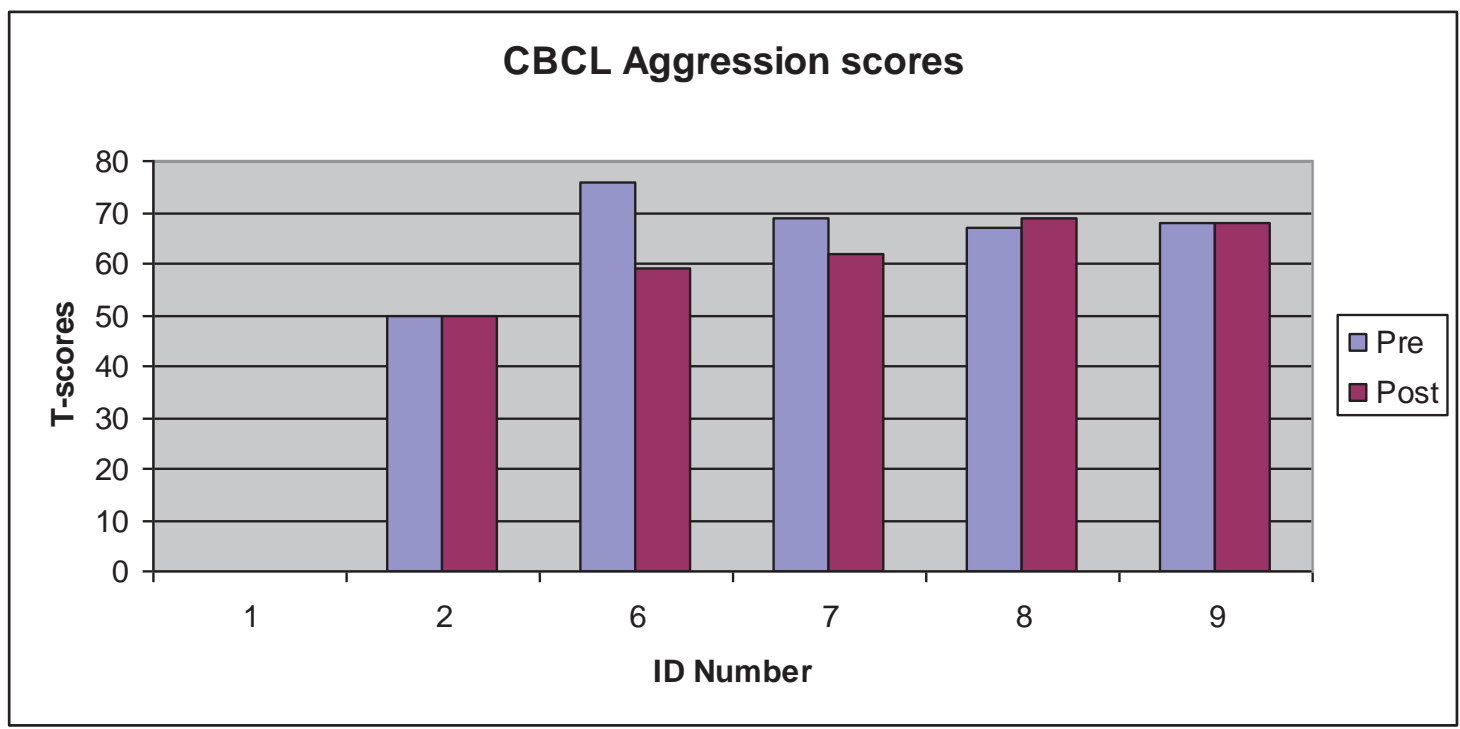


Figure 7. PSOC Total baseline (pre) and post-intervention scores

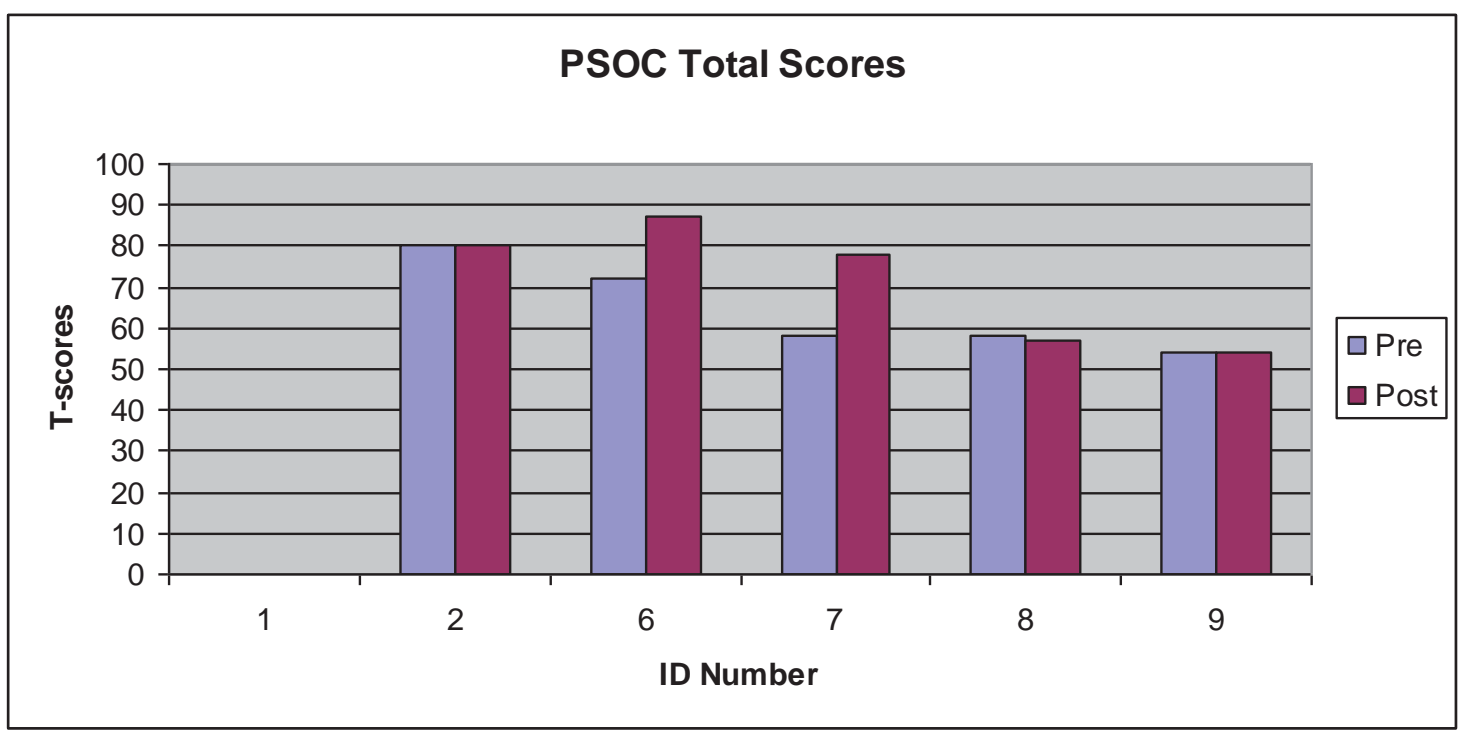


Figure 8. PSOC Satisfaction baseline (pre) and post-intervention scores

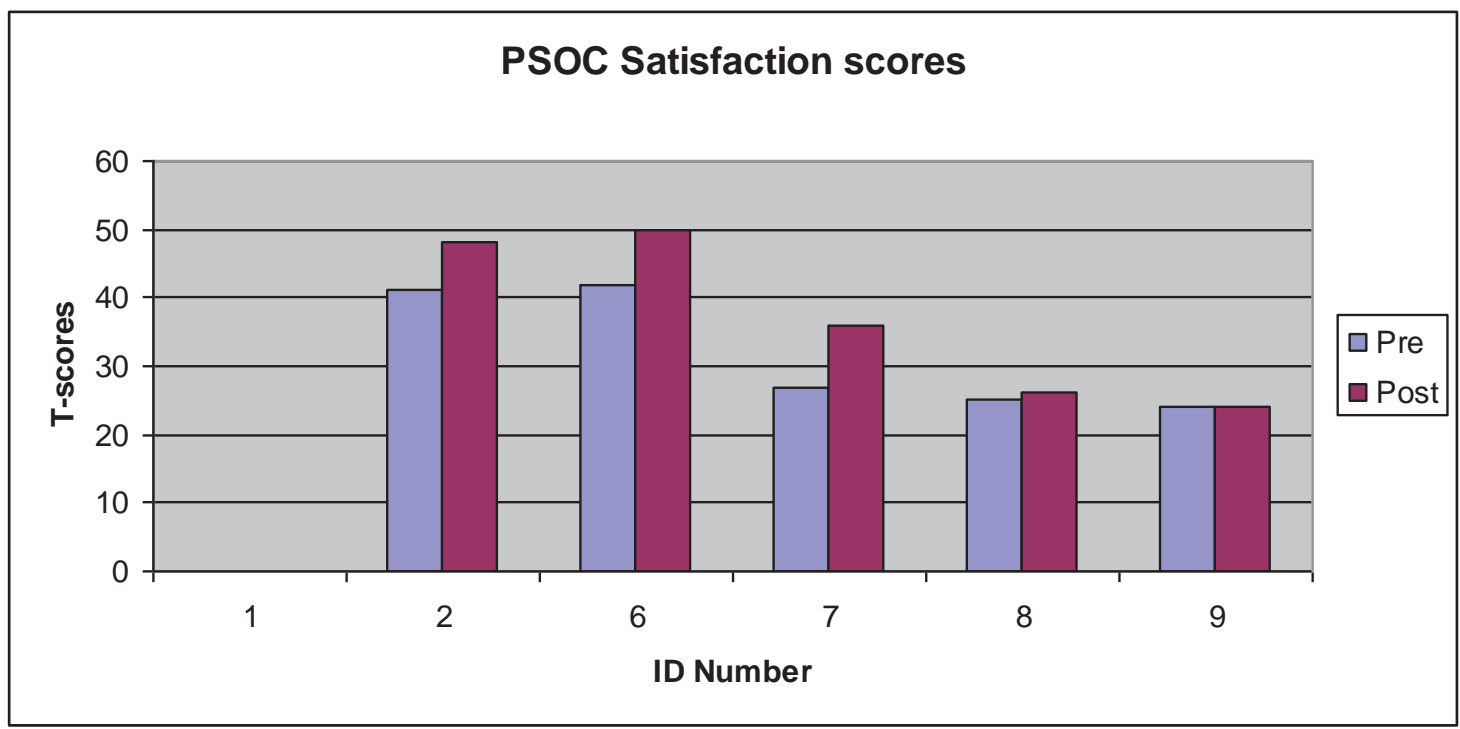


Figure 9. PSOC Efficacy baseline (pre) and post-intervention scores

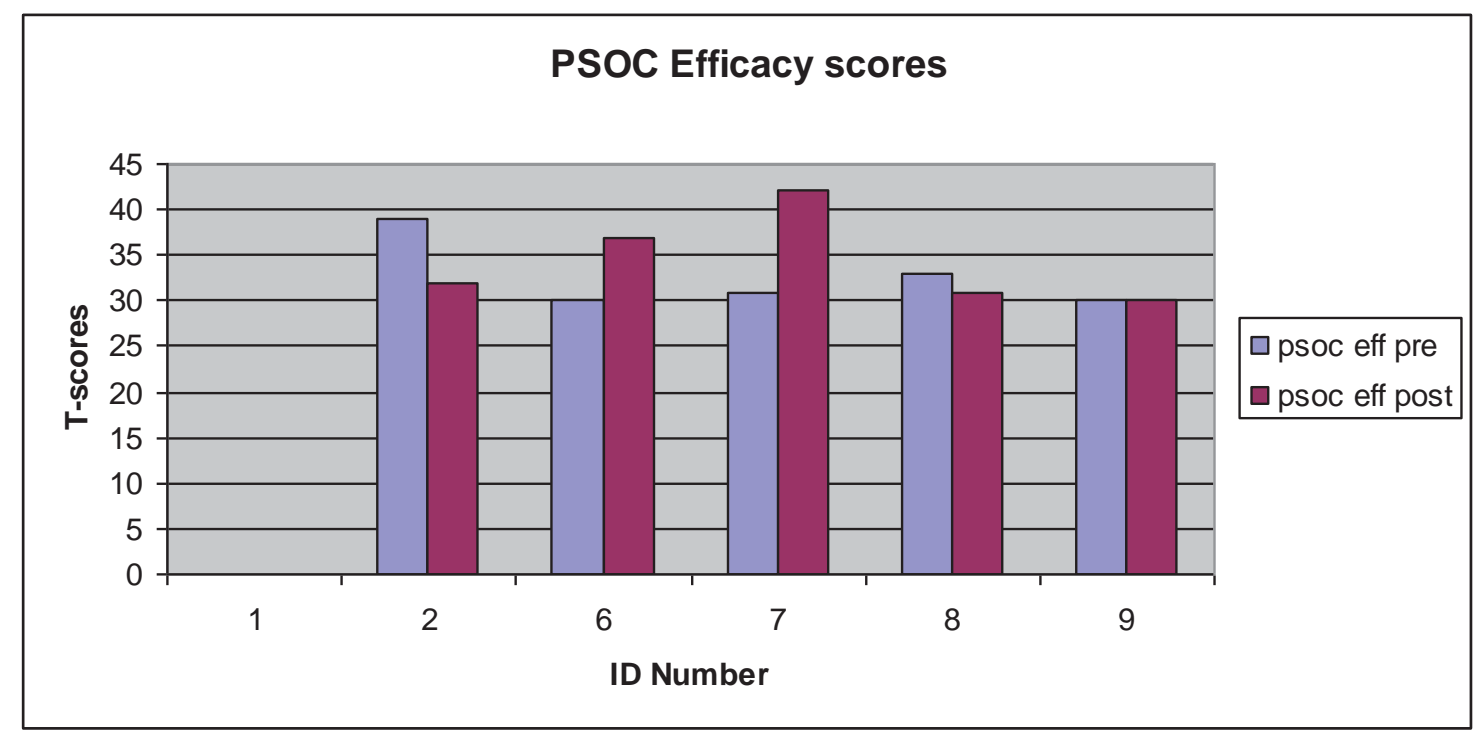


Figure 10. PARTS Total baseline (pre) and post-intervention scores

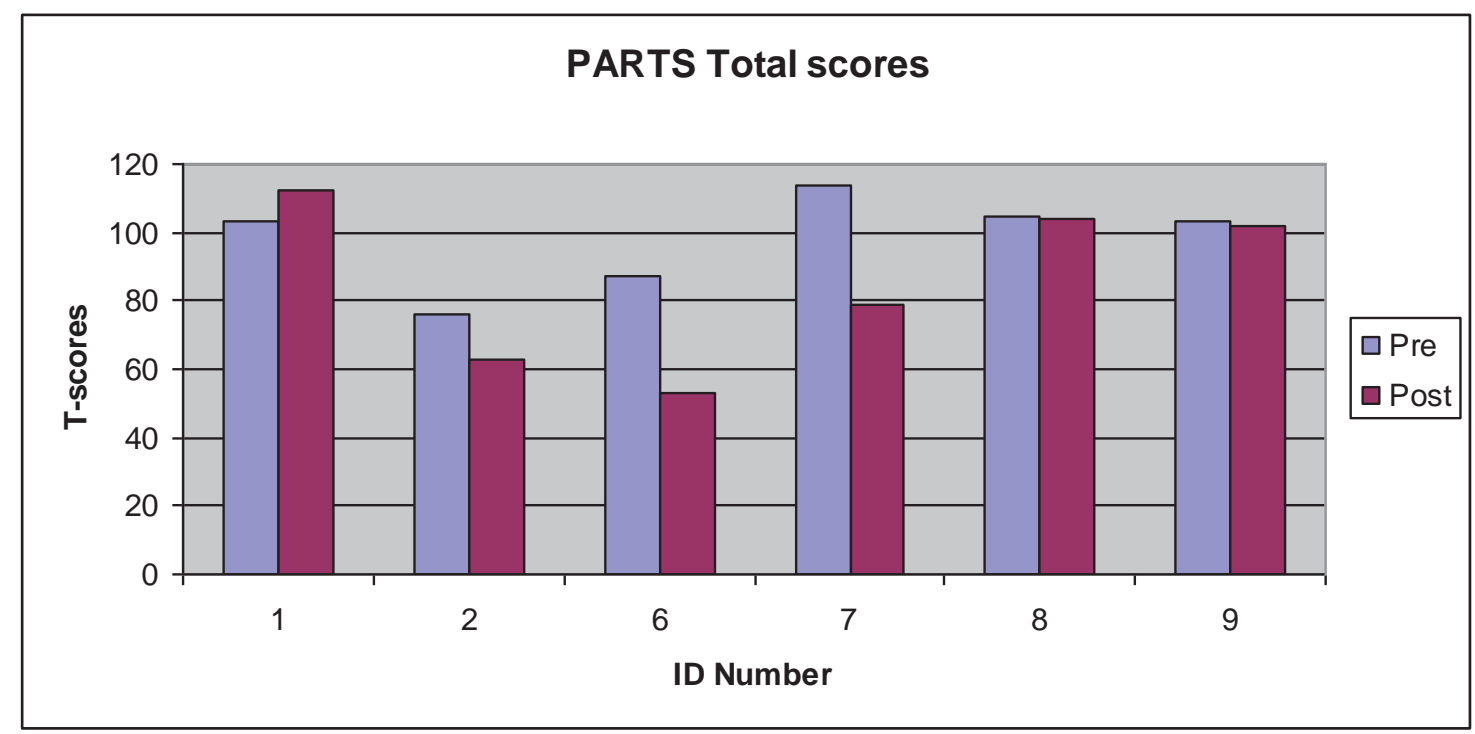


Figure 11. PARTS Laxness baseline (pre) and post-intervention scores

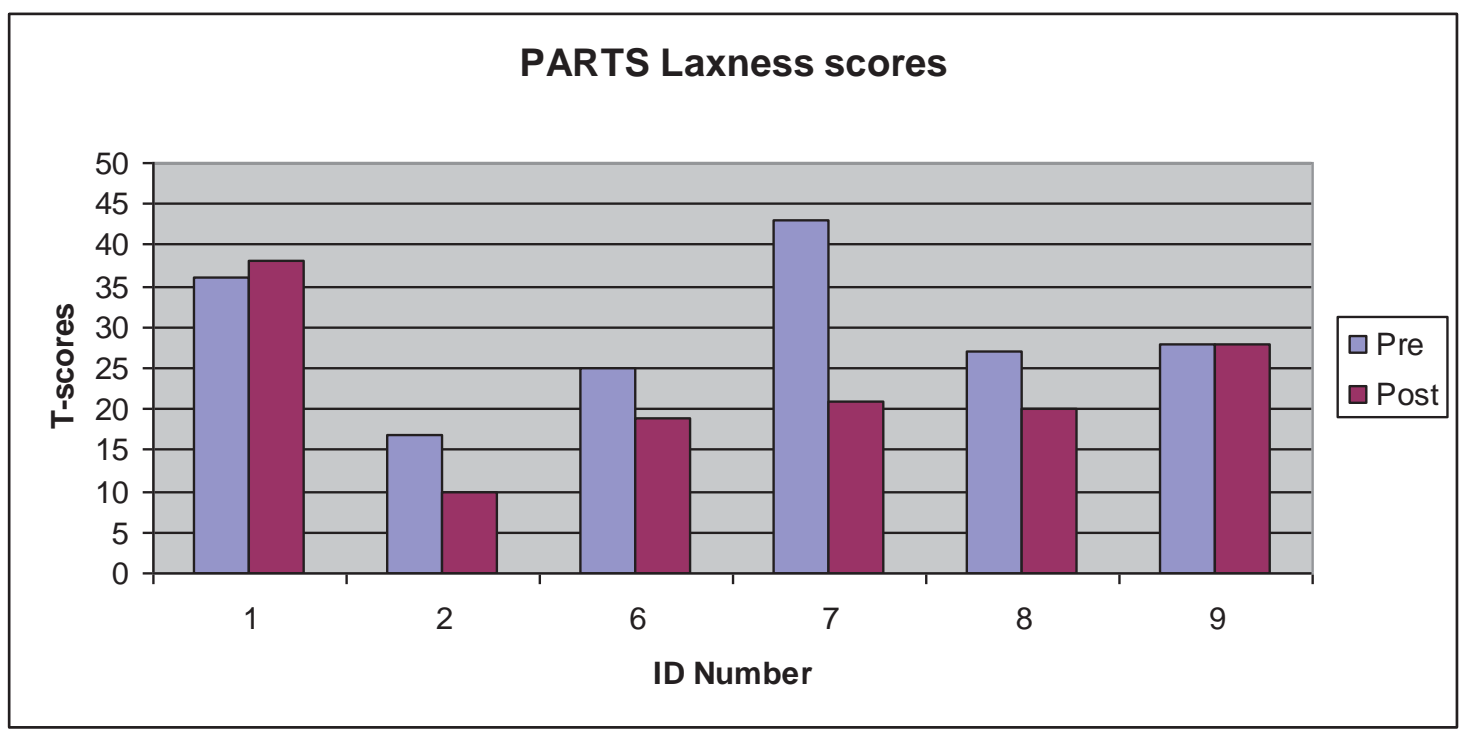


Figure 12. PARTS Overreactivity baseline (pre) and post-intervention scores

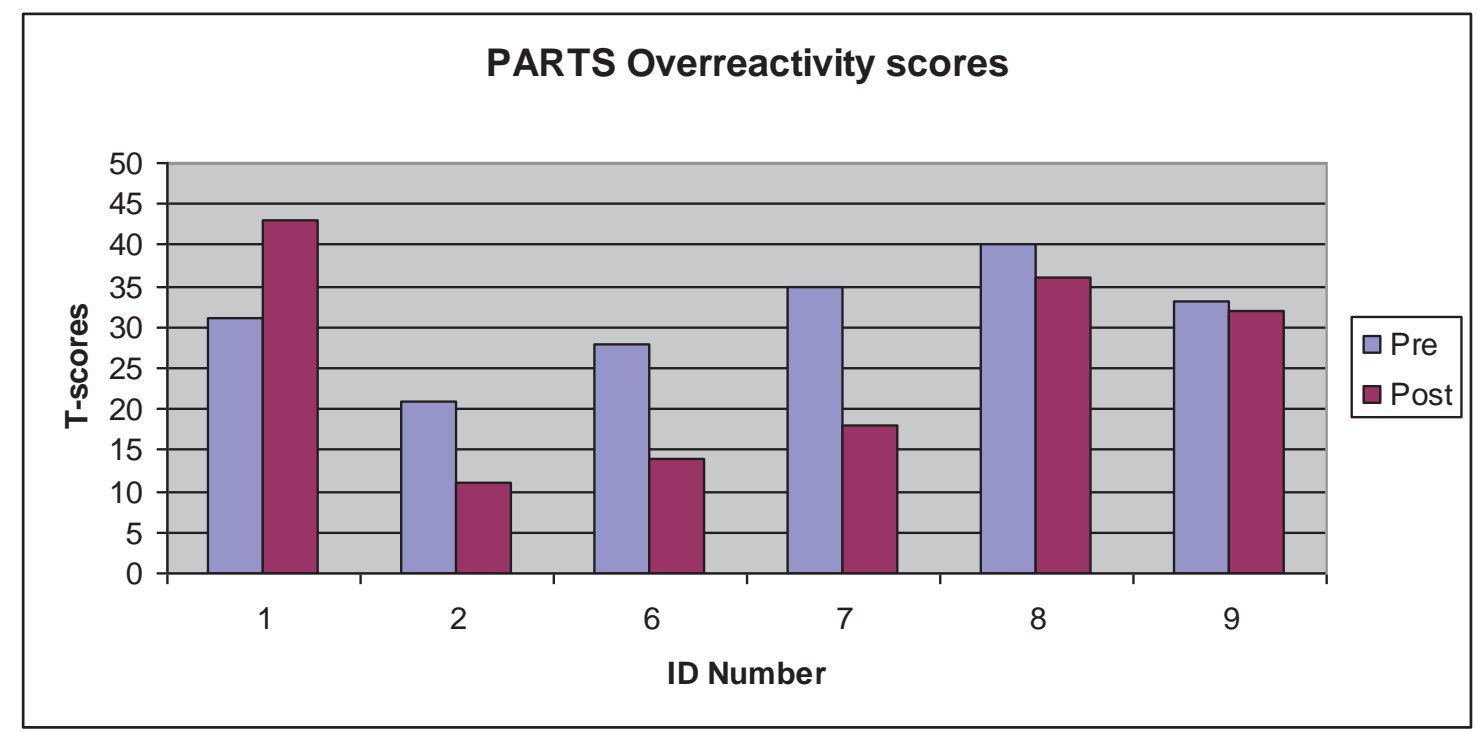


Figure 13. PARTS Verbosity baseline (pre) and post-intervention scores

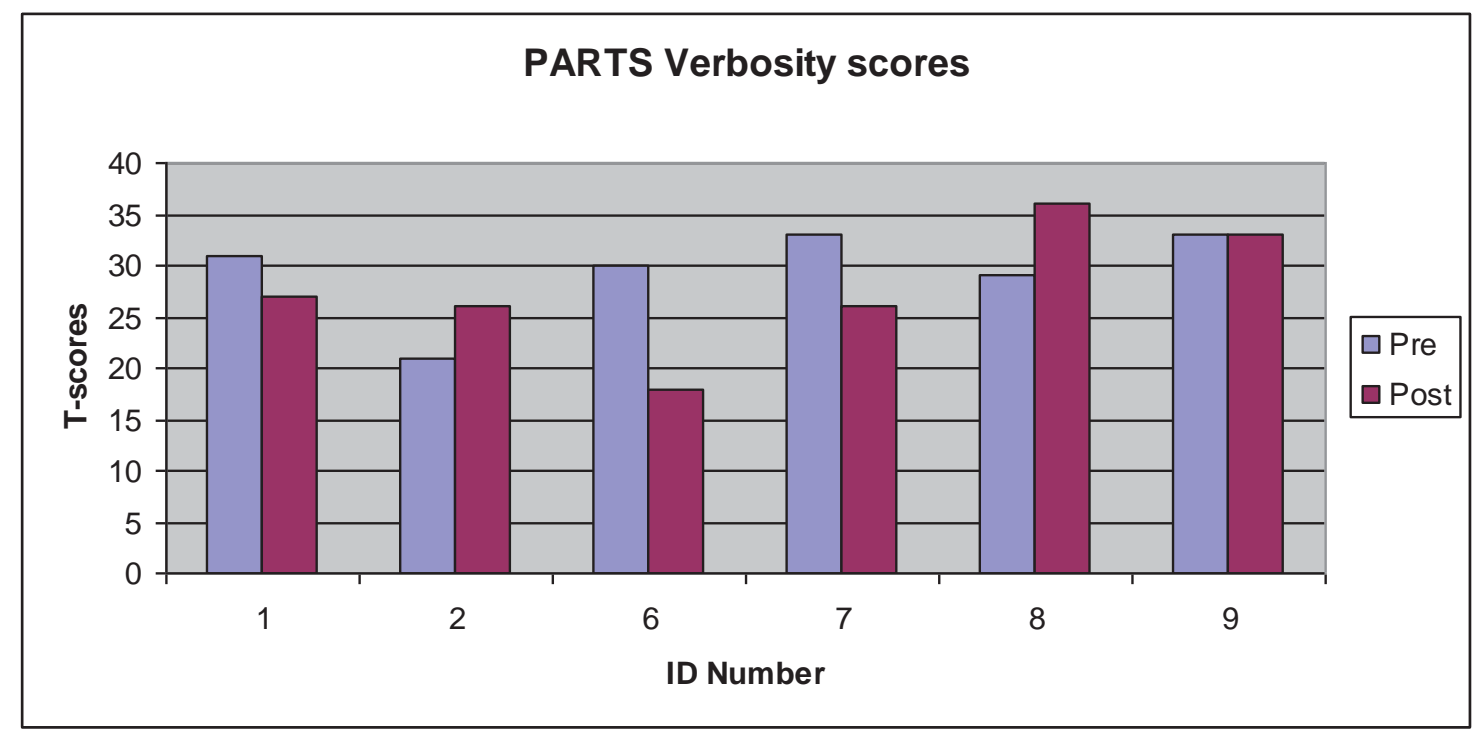


Figure 14. CES-D baseline (pre) and post-intervention scores

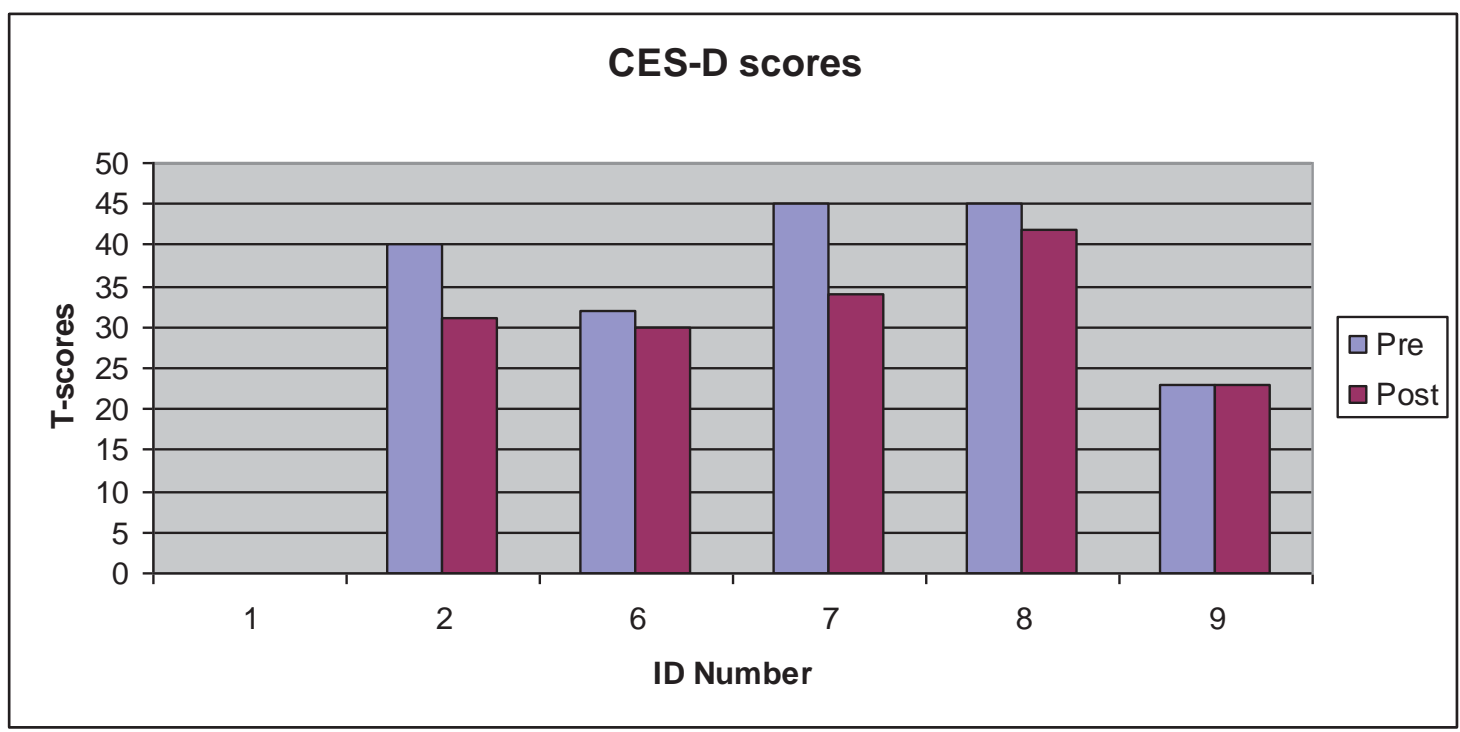




\section{References}

Achenbach, T. M., \& Rescorla, L. A. (2001). Manual for the ASEBA school-age forms and profiles: An integrated system of multi-informant assessment. Burlington, VT: Research Center for Children, Youth, and Families.

Alegria, M., Mulvaney-Day, N., Woo, M., Torres, M., Gao, S., \& Oddo, V. (2007). Correlates of past-year mental health service use among Latinos: results from the national Latino and Asian American study. American Journal of Public Health, 97 (1), 76-83.

American Psychiatric Association. (2000). Diagnostic and statistical manual of mental disorders (4th Ed.- Text Revision). Washington, DC: Author.

Arcia, E., Fernandez, M. C., Jaquez, M., Castillo, H., \& Ruiz, M. (2004). Modes of entry into services for young children with disruptive behaviors. Qualitative Health Research, 14 (9), 1211-1226.

Arcia, E., Skinner, M., Bailey, D., \& Correa, V. (2001). Models of acculturation and health behaviors among Latino immigrants to the US. Social Sciences \& Medicine, 53, 41-53.

Arnold, D. S., O'Leary, S., Wolff, L., \& Acker, M. (1993). The parenting scale (PARTS): A measure of dysfunctional parenting in discipline situations. Psychological Assessment, 5(2), 137-144.

Barlow, M., Wildman, B., \& Stancin, T. (2005). Mothers' help-seeking for pediatric psychosocial problems. Clinical Pediatrics, 44, 161-167.

Bauer, N., \& Webster-Stratton, C. (2006). Prevention of behavioral disorders in primary care. Current Opinion in Pediatrics, 18 (6), 654-659 
Belitz, J. \& Valdez, D. M. (1997). A sociocultural context for understanding gang involvement among Mexican-American male youth. In Psychological Interventions and Research with Latino Populations. Allyn \& Bacon: Needham Heights, MA.

Bernal, M. E., \& Castro, F. G. (1994). Are clinical psychologists prepared for service and research with ethnic minorities? American Psychologist, 49 (9), 797-805.

Blanchard, L.T., Gurka, M. J., \& Blackman, J. A. (2005). Emotional, developmental, and behavioral health of American children and their families: A report from the 2003 National Survey of Children's Health. Pediatrics,117 (6), e1202-1212.

Borowsky, I. W., Mozayeny, S., Stuenkel, K., \& Ireland, M. (2004). Effects of a primary care-based intervention on violent behavior and injury in children. Pediatrics, 114 , e392-399.

Breitenstein, S., Gross, D., Ordaz, I., Julion, W., Garvey, C., \& Ridge, A. (2007). Promoting mental health in early childhood programs serving families from low-income neighborhoods. Journal of the American Psychiatric Nurses Association, 13(5), 313-320.

Bromberger, J. T., Harlow, S. Avis, N., Kravitz, H. M., \& Cordal A. (2004). Racial/ethnic differences in the prevalence of depressive symptoms among middle-aged women: The study of women's health across the nation (SWAN). American Journal of Public Health, 94 (8), 1378-1385.

Brown, J. D., Wissow, L. S., Zachary, C., \& Cook, B. L. (2007). Receiving advice about child mental health from a primary care provider: African America and Hispanic parent attitudes. Medical Care, 45 (1), 1076-1082. 
Cauce, A. M., Domenech-Rodriguez, M., Paradise, M., Cochran, B. N., Shea, J. M., Srebnik, D., \& Baydar, N. (2002). Cultural and contextual influences in mental health help seeking: A focus on ethnic minority youth. Journal of Consulting and Clinical Psychology, 70 (1), 44-55.

Chow, J., Jaffee, K., \& Snowden, L. (2003). Racial/ethnic disparities in the use of mental health services in poverty areas. American Journal of Public Health, 93 (5), $792-797$.

Cicchetti, D., \& Rogosch, F. A. (1996). Equifinality and multifinality in developmental psychopathology. Developmental Psychopathology, 8, 597.

Coard, S. I. \& Holden, E. W. (1998). The effect of ethnic and racial diversity on the delivery of mental health services in pediatric primary care. Journal of Clinical Psychology in Medical Settings, 5 (3), 275-294.

Coatsworth, J., Pantin, H., \& Szapocznik, J. (2002). Familias Unidas: A familycentered ecodevelopmental intervention to reduce risk for problem behavior among Hispanic adolescents. Clinical Child and Family Psychology Review, 5 (2), 113-132.

Cook, B., McGuire, T., \& Miranda, J. (2007). Measuring trends in mental health care disparities, 2000-2004. Psychiatric Services, 58, 1533-1540.

Cortes, D. E., Rogler, L. H., \& Malgady, R. G. (1994). Biculturality among Puerto Rican adults in the United States. American Journal of Community Psychology, $22(5), 707$.

Cunningham, C. E., Bremner, R., \& Boyle, M. (1995). Large group communitybased parenting programs for families of preschoolers at risk for disruptive behavior 
disorders: utilization, cost effectiveness, and outcome. Journal of Child Psychology and Psychiatry, 36 (7), 1141-1159.

Dishion, T. J., Nelson, S. E., \& Kavanagh, K. (2003). The Family Check-Up for high-risk adolescents: Motivating parenting monitoring and reducing problem behavior. Behavior Therapy, 34, 553-571.

Dressler, W. W., \& Bernal, H. (1982). Acculturation and stress in a low-income Puerto Rican community. Journal of Human Stress, 8 (3), 32-8.

El-Ghoroury, N. H., Ramirez, L. Y., \& Bonny, A. (in preparation). A Hispanic clinic model.

Eyberg, S. (1993). Consumer satisfaction measures for assessing parent training programs. In Innovations in Clinical Practice: A Source Book (Volume 12). Professional Resource Press: Florida.

Eyberg, S. (1974). Therapy Attitude Inventory. Available from the author, University of Florida, Gainesville, FL.

Eyberg, S. M., \& Robinson, E. A. (1982). Parent-child interaction training: effects on family functioning. Journal of Clinical Child Psychology, 11 (2), 130-137.

Flores, G., Fuentes-Afflick, E., Barbot, O., Carter-Pokras, O., Claudio, L., Lara, M., McLaurin, J. A., Pachter, L., Gomez, F. R., Mendoza, F., Valdez, R. B., Villarruel, A. M., Zambrana, R. E., Greenberg, R., \& Weitzman, M. (2002). The health of Latino children: urgent priorities, unanswered questions, and a research agenda. Journal of the American Medical Association, 288 (1), 82-90. 
Foster, E. M., Jones, D. E., \& the Conduct Problems Prevention Research Group. (2005). The high costs of aggression: public expenditures resulting from conduct disorder. American Journal of Public Health, 95 (10), 1767-1772.

Frazier, S. L., Formoso, D., Birman, D., \& Atkins, M. S. (2008). Closing the research to practice gap: Redefining feasibility. Clinical Psychology: Research and Practice, 15 (2), 125-129.

Gerdes, A. C. \& Schneider, B. W. (2009). Evidence-based ADHD treatment with a Spanish-speaking Latino family. Clinical Case Studies, 8, 174-192.

Gilmore, L. \& Cuskelly, M. (2008). Factor structure of the Parenting Sense of Competence scale using a normative sample. Child: Care, Health and Development, 35 (1), 48-55.

Glascoe, F. P. (1997). Parents’ Evaluation of Developmental Status (PEDS). Nashville, TN: Ellsworth \& Vandemeer Press.

Glasgow, R.E., Lichtenstein, E., \& Marcus, A. C. (2003). Why don`t we see more translation of health promotion research to practice? Rethinking the efficacy-toeffectiveness transition. American Journal of Public Health, 93 (8), 1261-1267.

Gross, D., Conrad, B., Fogg, L., \& Wothke, W. (2007). A longitudinal model of maternal self-efficacy, depression, and difficult-temperament. Research in Nursing and Health, 17 (3), 207-215.

Gross, D., Julion, W., \& Garvey, C. (2003). The Chicago Parenting Program of Rush University: Group Leader Manual. Chicago, IL: Rush University. 
Guarnaccia, Angel, \& Worobey . (1989). The factor structure of the CES-D in the Hispanic health and nutrition examination survey: the influences of ethnicity, gender and language. Social Science and Medicine, 29, 85.

Guevara, J., Rothbard, A., Shera, D., Zhao, H., Forrest, C., Kelleher, K., \& Schwartz, D. (2007). Correlates of behavioral care management strategies used by primary care pediatric providers. Ambulatory Pediatrics , 7 (2), 160 - 166.

Harnish, J. D., Dodge, K. A., \& Valente, E. (1995). Mother-child interaction quality as partial mediator of the roles of maternal depressive symptomatology and socioeconomic status in the development of child behavior problems. Child Development, 66, 739-753.

Harvey, E., Danforth, J. S., Ulaszek, W. R., \& Eberhardt, T. L. (2001). Validity of the parenting scale for parents of children with attention-deficit/hyperactivity disorder. Behaviour Research and Therapy, 39, 731-743.

Hawkins-Walsh, E. (2001). Turning primary care providers` attention to child behavior: a review of the literature. Journal of Pediatric Health Care, 15 (3), 115-122.

Helfenbaum-Kun, E. D. \& Ortiz, C. (2007). Parent-training groups for fathers of Head Start Children: A pilot study of their feasibility and impact on child behavior and intra-familial relationships. Child \& Family Behavior Therapy, 29 (2), 47-64.

Ho, J., Yeh, M., McCabe, K., \& Hough, R. L. (2007). Parental cultural affiliation and youth mental health service use. Journal of Youth and Adolescence, 36, 529-542.

Johnston, C., \& Mash, E. (1989). A measure of parenting satisfaction and efficacy. Journal of Clinical Child Psychology, 18(2), 167-175. 
Jones, T. L., \& Prinze, R. J. (2005). Potential roles of parental self-efficacy in parent and child adjustment: a review. Clinical Psychology Review, 25, 341-363.

Kaizar, E., Chisolm, D., Seltman, J., Greenhouse, J., \& Kelleher, K. J. (2006). The role of care location in diagnosis and treatment of pediatric psychosocial conditions. Journal of Developmental \& Behavioral Pediatrics, 27(3), 219-225.

Kazak, A. E., Simms, S., Alderfer, M. A., Rourke, M. T., Crump, T., McClure, K., Jones, P., Rodriguez, A., Boeving, A., Hwang, W-T, \& Reilly, A. (2005). Feasibility and preliminary outcomes from a pilot study of a brief psychological intervention for families of children newly diagnosed with cancer. Journal of Pediatric Psychology, 30 (8), 644-655.

Kumpfer, K. L., \& Alvarado, R. (2003). Family-strengthening approaches for the prevention of youth problem behaviors. American Psychologist, 58 (6/7), 457-465.

Lavigne, J. V., LeBailly, S. A., Gouze, K. R., Cicchetti, C., Jessup, B. W., Arend, R., Pochyly, J., \& Binns, H. (2008a). Predictor and moderator effects in the treatment of oppositional defiant disorder in primary care. Journal of Pediatric Psychology, 33 (5), 462-472.

Lavigne, J. V., LeBailly, S. A., Gouze, K. R., Cicchetti, C., Pochyly, J., Arend, R., Jessup, B. W., \& Binns, H. (2008b). Treating oppositional defiant disorder in primary care : a comparison of three models. Journal of Pediatric Psychology, 33 (5), 449-461.

Lieberman, A., Adalist-Estrin, A., Erinle, O., \& Sloan, N. (2006). On-site mental health care: a route to improving access to mental health services in an innercity, adolescent medicine clinic. Child Care: Health \& Development, 32 (4), 407-413. 
Lochman, J. E. (2000). Parent and family skills training in targeted prevention programs for at-risk youth. The Journal of Primary Prevention, 21 (2), 253-265.

Loukas, A., Suizzo, M., \& Prelow, H. (2007). Examining resource and protective factors in the adjustment of Latino youth in low income families: what role does maternal acculturation play? Journal of Youth Adolescence, 36, 489-501.

Manongdo, J., \& Garcia, J. (2007). Mothers' parenting dimensions and adolescent externalizing and internalizing behaviors in a low-income, urban MexicanAmerican sample. Journal of Clinical Child and Adolescent Psychology, 36 (4), 593 604.

Martinez, C., \& Eddy, J. (2005). Effects of culturally adapted parent management training on Latino youth behavioral health outcomes. Journal of Consulting and Clinical Psychology, 73 (5), 841-851.

Masi, C. M., Hawkley, L. C., Piotrowsky, Z. H., \& Pickett, K. E. (2007). Neighborhood economic disadvantage, violent crime, group density, and pregnancy outcomes in a diverse, urban population. Social Science \& Medicine, 65 (12), 24402457.

Matos, M., Bauermeister, J. J., \& Bernal, G. (2009). Parent-child interaction therapy for Puerto Rican preschool children with ADHD and behavior problems: A pilot efficacy study. Family Process, 48 (2), 232-252.

Neary, E. M. \& Eyberg, S. M. (2002). Management of disruptive behavior in young children. Infants \& Young Children, 14 (4), 53-67. 
Nordstrom, A. H., Dumas, J.E., \& Gitter, A. H. (2008). Parental attributions and perceived intervention benefits and obstacles as predictors of maternal engagement in a preventive parenting program. NHSA Dialog, 11 (1), 1-24.

Ohan, J. L., Leung, D. W., \& Johnston, C. (2000). The Parenting Sense of Competence Scale: Evidence of a stable factor structure and validity. Canadian Journal of Behavioural Sciences, 32 (4), 251-261.

Pachter, L. M., Auinger, P., Palmer, R., \& Weitzman, M. (2006). Do parenting and the home environment, maternal depression, neighborhood, and chronic poverty affect child behavioral problems differently in different racial-ethnic groups? Pediatrics, 117 (4), 1329-1338.

Pisterman, S., Firestone, P., McGrath, P., Goodman, J. T., Webster I., Mallory, R., \& Goffin, B. (1992). The effects of parent training on parenting stress and sense of competence. Canadian Journal of Behavioural Science, 24 (1), 41-58.

Radloff, L. S. (1977). The CES-D scale: A self-report depression scale for research in the general population. Applied Psychological Measurement, 1 (3), 385-401.

Rawal, P., Romansky, J., Jenuwine, M., \& Lyons, J. S. (2004). Racial differences in the mental health needs and service utilization of youth in the juvenile justice system. Journal of Behavioral Health Services \& Research, 31 (3), 242-254.

Rubio-Stipec, M., Bird, H., Canino, G., \& Gould, M. (1990). The internal consistency and concurrent validity of a Spanish translation of the Child Behavior Checklist. Journal of Abnormal Child Psychology, 18 (4), 393. 
Sanders, M. R., Turner, K. M. T., \& Markie-Dadds, C. (2003). The development and dissemination of the Triple P-Positive Parenting Program: A multilevel, evidencebased system of parenting and family support. Prevention Science, 3 (3), 173-189.

Santor, D. A., Zuroff, D. C., Ramsay, J. O., Cervantes, P., \& Palacios, J. (1995). Examining scale discriminability in the BDI and CES-D as a function of depressive severity. Psychological Assessment, 7 (2), 131-139.

Sentell, T., Shumway, M., \& Snowden, L. (2007). Access to mental health treatment by English language proficiency and race/ethnicity. Journal of General Internal Medicine, 22, 289-293.

Siegmann, R. M., \& Long, G. M. (1995). Psychoeducational group therapy changes the face of managed care. Journal of Practical Psychiatry and Behavioral Health, 1, 29-36.

Smokowski, P., \& Bacallao, M. (2006). Acculturation and aggression in Latino adolescents: a structural model focusing on cultural risk factors and assets. Journal of Abnormal Child Psychology, 34, 659-673.

Stancin, T., Perrin, E., \& Ramirez, L. Y. (2009). Pediatric psychology and primary care. In M. C. Roberts (Ed.), Handbook of Pediatric Psychology, Fourth Edition. The Guilford Press, New York.

Steele, R. G., Nesbitt-Daly, J. S., Daniel, R. C., \& Forehand, R. (2005). Factor structure of the Parenting Scale in a low-income African American sample. Journal of Child and Family Studies, 14 (4), 535-549. 
Stevens, G. D., \& Lee, S. ( 2003). Racial and ethnic disparities in the primary care experiences of children: A review of the literature. Medical Care Research and Review, 60 (1), 3-30.

Takeuchi, D. T., Sue, S., \& Yeh, M. (1995). Return rates and outcomes from ethnicity-specific mental health programs in Los Angeles. American Journal of Public Health, 85 (5), 638-643.

Tremblay, R. E., Nagin, D. S., Seguin, J. R., Zoccolillo, M., Zelazo, P. D., Boivin, M., Perusse, D., \& Japel, C. (2004). Physical aggression during early childhood: trajectories and predictors. Pediatrics, 114, e43-50.

US Census Bureau. (2008a). U.S. Latino Population Surpasses 45 Million. Washington, DC: US Census Bureau News, US Department of Commerce. US Census Bureau. (2008b). Facts for Features: Latino Heritage Month $2008 .$. Washington, DC: US Census Bureau News, US Department of Commerce.

US Department of Health and Human Services. (1999) Mental Health: A Report of the Surgeon General. Rockville, MD: US Department of Health and Human Services, Substance Abuse and Mental Health Services Administration, Center for Mental Health Services, National Institutes of Health, National Institute of Mental Health.

US Department of Health and Human Services. (2003). Family Psychoeducation: Implementation Resource Kit. Rockville, MD: US Department of Health and Human Services, Substance Abuse and Mental Health Services Administration, Center for Mental Health Services, National Institutes of Health, National Institute of Mental Health. 
US Department of Health and Human Services. (2001). Mental Health: Culture, Race, and Ethnicity - A supplement to Mental Health: A Report of the Surgeon General. Rockville, MD: US Department of Health and Human Services, Substance Abuse and Mental Health Services Administration, Center for Mental Health Services, National Institutes of Health, National Institute of Mental Health.

US Public Health Service. (2000). Report of the Surgeon General's Conference on Children's Mental Health: A National Action Agenda. Washington, DC: US Department of Health and Human Services.

Van Camp, C. M., Vollmer, T. R., Goh, H-L., Whitehouse, C. M., Reyes, J., Montgomery, J. L., \& Borrero, J. C. (2008). Behavioral parent training in child welfare: evaluations of skills acquisition. Research on Social Work Practice, 18 (5), 377.

Webster-Stratton, C. (2000). The Incredible Years: parents, teachers and children training series. Residential Treatment for Children \& Youth, 18 (3), 31-45.

Wells, A. M., Garvin, V., Dohm, F-A. \& Striegel-Moore, R. H. (1997). Telephone-based guided self-help for binge eating disorder: a feasibility study. International Journal of Eating Disorders, 21 (4), 341-346.

Wierzbicki, M. J., \& Pekarick, G. (1993). A meta-analysis of psychotherapy dropout. Professional Psychology Research Practice, 24, 190-195.

Wood, P. A., Yeh, M., Pan, D., Lambros, K. M., McCabe, K. M., \& Hough, R. L. (2005). Exploring the relationship between race/ethnicity, age of first school-based services utilization, and age of first specialty mental health care for at-risk youth. Mental Health Services Research, 7 (3), 185-196. 
Yasui, M., \& Dishion, T. J. (2007). The ethnic context of child and adolescent problem behavior: implications for child and family interventions. Clinical Child and Family Psychology, 10 (2), 137-179.

Zabinski, M. F., Wilfley, D. E., Pung, M. A., Winzelberg, A. J., Eldredge, K., \& Taylor, C. B. (2001). A interactive internet-based intervention for women at risk of eating disorders: a pilot study. International Journal of Eating Disorders, 30, (2), 129137.

Zeltzer, L. K., Tsao, J. C. I., Stelling, C., Powers, M., Levy, S., \& Waterhouse, M. (2002). A phase I study on the feasibility and acceptability of an acupuncture/hypnosis intervention for chronic pediatric pain. Journal of Pain and Symptom Management, 24 (4), 437-446. 